\title{
Experimental approach to modeling of the plasticizing operation in the hot plate welding process
}

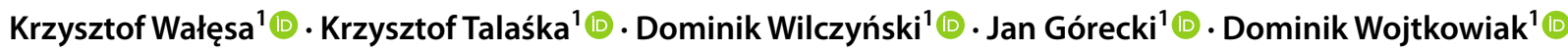

Received: 8 April 2021 / Revised: 20 October 2021 / Accepted: 3 November 2021 / Published online: 30 November 2021

(c) The Author(s) 2021

\begin{abstract}
The paper discusses the topic of butt welding of polyurethane drive belts by the hot plate method in the context of modeling the process of this technological operation. Based on the analysis of the butt welding process, a series of studies of the thermomechanical properties of the material from which the belt is made has been planned. The results will be used for mathematical modeling of the welding process, and in particular its most important phase: the plasticizing operation. On this basis, the study of the compression of cylindrical specimens taken from the belt has been performed at two different speeds. Their result is the relationship between the compressive stress $\sigma_{\mathrm{c}}$ and the modulus of longitudinal elasticity $E_{\mathrm{c}}$ at compression and: deformation $\varepsilon_{\mathrm{c}}$, temperature value $T$, as well as the compressive velocity $v_{\mathrm{c}}$. In the next step, dynamic viscosity $\eta$ of the belt material was determined based on the results of dynamic thermomechanical analysis. The research work culminated in the attempts to plasticize the material on a hot plate, in conditions similar to the process of industrial welding. These studies were performed at different speeds $v_{\mathrm{pl}}$, resulting in the correlation between the force required for plasticizing $F_{\mathrm{pl}}$ and the value of the speed of the belt end $v_{\mathrm{pl}}$ relative to the hot plate heated to a temperature $T_{\mathrm{p}}$. The obtained results will be used to formulate a mathematical model of plasticizing the material, based on the selected mechanical deformation models.
\end{abstract}

Keywords Hot plate welding · Belts welding · Round drive belts · Polyurethane belts - Thermomechanical parameters · Compression tests $\cdot$ Plasticizing process $\cdot$ Viscosity designation

\section{Introduction}

\subsection{Source of the research problem}

Endless belts with a circular cross section and a diameter of several millimeters, made of thermoplastic elastomers, are widely used in the driving and transporting systems in industrial machines [1], similar to perforated transporting belts with a rectangular cross section [2]. That is why they are often offered by leading belt manufacturers [3]. The process of their production is two-stage [4]. In the first stage, the belt band with a length of several hundred meters is produced by continuous extrusion. This action ends with its winding on the reel, which facilitates transport and storage. The final step in the production of a finished drive or conveyor belt is to cut to the appropriate length and make a

Krzysztof Wałęsa

krzysztof.walesa@put.poznan.pl

1 Institute of Machine Design, Poznan University of Technology, Piotrowo Street 3, 61-138 Poznan, Poland permanent connection of its ends, to obtain a tight belt band with a closed circumference and uniform geometry along the entire length [5].

In many cases, the connection of the ends of the belt is carried out by butt welding using the hot plate method. This method is known as one of the cheapest and the easiest ways of joining thermoplastic materials, both for general industrial purposes [6] and in some specialized industries, for example in medical devices manufacturing [7]. This process is usually carried out manually, using dedicated, simple tools [3]. Unfortunately, this operation usually does not provide a satisfactory repeatability of the geometric dimensions of the product after the connection, as well as high-quality weld. This is mainly due to the manual application of the force needed to plasticize and join the ends of the belt, which does not ensure the repeatability of the conditions for carrying out this operation [8]. To avoid this phenomenon, there is a need for automating this process and a requirement to introduce special control methods. In industrial practice, for example, these ideas can be realized using the non-contact heating operation [9] or by restriction of the displacement 
of welded elements during their movement [10]. There is also a third solution - controlling only the displacement of welded elements. This can be realized in the easiest way in industrial practice.

In response to the demand of the industry for the automation of the process of butt welding of drive belts, the authors have proposed a design solution for an automatic belt welding machine. The correct configuration of the control system requires the development and verification of technological parameters of the welding process. This is essential for:

- properly describing physical phenomena which occur during welding [1], which will allow performing the process in the most effective way possible,

- properly controlling the mechanical equipment in the designed machine [4],

- properly planning the course of technological operations accompanying welding, e.g., cutting the belt to the appropriate length or cutting the flash [5].

In this context, research work has been undertaken on butt joint welding of drive belts, in particular on the operation of plasticizing the material. Its ultimate goal is to develop a mathematical model of this process.

\subsection{Current state of knowledge about hot plate welding}

Research on butt welding of plastics has already been carried out many times in various aspects. Watson [11] investigated the process of welding plastics in the form of tanks made of polypropylene, polystyrene or polyphenylene oxide. They showed the correlation between the strength of the joint and the technological parameters of the bonding process in an experimental way. Results of their research provided information about the significant positive influence of heating time on the strength of the joint, especially for polypropylene. In addition, influences of heating pressure, heating displacement and consolidation pressure are ambiguous, and strongly depend on the material. Polyphenylene oxide can be characterized by the most stable response for changing the process parameters. Gehde [12] conducted research on the welding of perpendicular beams made of different types of polypropylene in the context of the analysis of joint defects formed during welding with different parameters. During studying the conclusions of their work, we can learn that bond failure mechanisms strongly depend not only on the type of material but also on the welding parameters. Particularly noteworthy is the fact that increasing the joining pressure could give a strength-increasing effect, but the excessive value of this parameter can cause a crack in the joint cross section. Stokes conducted advanced research on plastics welding, which was based mainly on determining the correlation between the relative strength of the welded joint and the process parameters. He conducted research on polycarbonate [10]. As the results of this work, we can find a lot of information about weld strength and failure strain depending on the hot plate temperature, heating and sealing time, and state of sample preparation status. The research was conducted using the hybrid approach: pressure-displacement-controlled welding, using mechanical stops to restrict maximal displacement of material during operation. Research results are a kind of database of welding parameters for rigid polycarbonate. In other works, this researcher obtains similar results for: polycarbonate, polyetherimide, and poly(butylene terephthalate) [13]. Using the same methodology, Stokes obtained a kind of database of weld strength and failure strain for a lot of standard polymer materials (e.g., ABS, PA, PEI, etc.) [14]. It is worth noticing that these studies were carried out with an innovative method of process control-pressure-controlled with a limitation of the movement of the welded element. The second group of his main achievements concerned the experimental comparison of the results of the hot plate welding and vibration welding of rigid thermoplastics: polyamides [15], ABS [16], and poly(vinyl chloride) [17]. Concluding these three papers which are also kinds of databases, we can say that for these materials, using vibration welding we can obtain joints with higher relative strength (where average strength can achieve almost $100 \%$ of bulk strength), than using the hot plate welding (for which joint strength can achieve even more than $100 \%$, but average values are much lower). Potente also research about the hot plate welding process, but in this case, his work mainly concerns mathematical modeling and process optimization, using thermodynamic and rheological models. In [18] authors showed derivation of the mathematical model for one-dimensional hot plate welding operation of rigid, thermoplastic material. Their model was validated by the experimental procedure. This work shows a very important issue related to hot plated welding: the complex nature of thermal interaction between hot plate, welded material, and environment. First, there is conduction between the welded material and the hot plate and also between the welded sample and grips used for holding the sample. For the second, there is convection between the hot plate, sample, and the environment. The presence of this phenomenon is due to the atmospheric environment. At last, there is radiation from the sample and the hot plate. Researchers proved that these actions have influence on final temperature distribution during the process. This parameter in turn has a great influence on the process and final joint strength. These works were continued in [19] with the added stress calculations. This author also carried out research on the formation of the effective geometry of the contact surfaces in joined elements before the connection process [20], in which it was proved that shaping of the 
head surfaces of joined elements does not give any positive effect on the final weld strength. Almost the same results were obtained by Liu [21], who gained an almost constant correlation between relative weld strength and interface shape. Using the same relations as in the model derivation [18], Potente also worked on scaling-up thermodynamic and rheological laws to simplify the hot plate welding model. As results, there is a model for rigid materials which uses non-dimensional coefficients [22]. Potente also conducted research about optimization of the hot plate welding process in different aspects: using computer-aided design tools [23] and for use in self-optimizing heated-tool welder [24]. In cooperation with Schneiders, he also worked on high-speed hot plate welding using a designed machine [25]. All of his impressive work can be characterized by three main features:

- he proved that considering all of the thermal phenomena (conduction, convection, and radiation) is important for proper modeling of this process,

- all obtained models are used for welding rigid plastics (ABS, PC, PMMA, PE-HD),

- due to this fact, the general principle of the welding operation, which is modeled for this applications, is based on a pressure-controlled mechanism, without controlling the displacement.

Nonhof [26] and Cocard [27], similarly to Potente worked on optimizing the welding process for pressure-controlled welding. Poopat conducted a lot of work connected with the hot plate welding process, referring to contact [28] as well as contactless [29] ways to carry out this technological operation. From his experimental considerations, the characteristics of joint strength vs. melt layer thickness, and melt layer thickness vs. heating time and temperature can be obtained. These papers can be treated as a database of sorts for welding HDPE using pressure-controlled hot plate welding. Mokhtarzadeh also carried out a number of research activities in the area of butt welding of plastics, including analysis of welding and comparison of other types of welding with the hot plate method, in terms of quality and strength of the joint, for two similar materials [30] as well as for two different materials [31]. Riahi conducted research on plasticizing polyethylene [32] also using analytical and numerical modeling. The main goal of his research was to estimate the strength of the welds in the function of welding time and the hot plate temperature. Oliveira conducted research on plasticizing polypropylene in order to estimate the size and structure of the flash, depending on the process parameters, both for monolithic [8] and for glass-reinforced polypropylene [33]. A lot of researchers conducted work concerning one of the most important operations from the hot plate welding cycle-material plasticizing. Wood [34] attempted to model the operation of plasticizing a rigid polymer using flow continuity equations and a classical thermodynamic approach. Yoo [35] obtained the model of plasticizing the rigid pipes using the finite element method including Galerkin's solutions. Ezekoye and Nieh using the theory of polymer chain diffusion [36] and thermodynamic similarity numbers [37], gained simplified models of plasticizing and prediction of the weld strength. Lee [38] experimentally obtained the correlation between the degree of plasticity of the material and the process parameters, using some specific methods, e.g., differential scanning calorimetry or thermogravimetric analysis. During literature analysis, it can be noticed that the heat exchange during the hot plate welding process is a very important issue. Savija [39] and Kim [40] analyzed the contact thermal resistance between two surfaces, especially for hot plate welding purposes. Myers [41] and Poslinski [42] investigated the heat exchange between a hot plate and a heated polymer in the context of hot plate welding using the heat exchange laws.

Analysis of the current state of knowledge about the technological process of hot plate welding indicates that the research work undertaken so far relates to butt welding of classic plastics with thermoplastic properties and relatively high rigidity at standard environment temperature (polyamide, polycarbonate, polyethylene and polypropylene). In addition, the cases of butt welding cited in the literature mostly concern elements with a relatively complex crosssectional shape, as a result of which their susceptibility to buckling is low. Therefore, it is common to model the butt welding process as a set of compression operations of the welded material under variable temperature conditions. These phenomena occur in the first stages of the process, when the material is plasticized, and then when the melted surfaces are pressed together. The natural result of this approach to the process description is to analyze the force (or pressure) of material pressure in the various process phases. This approach is common in the works of many authors [11-33], regardless of the deviations in the final, practical implementation of the process, which consist, for example, in the use of displacement limiters of the plasticized element [10,13-17]. This translates directly into industrial applications where it is common to use force or pressure adjustments to maintain fixed, well-defined values of these parameters in the various process stages.

\subsection{Author's approach to hot plate welding process of drive belts}

According to the authors, hot plate welding of drive belts, carried out in an automated manner, requires a different approach. The relatively small diameters of the welded product and the low stiffness of the material make it difficult to precisely control the pressing force of the material during plasticizing in industrial production conditions. A 
much better solution in this case seems to be to control the movement and the speed of the belt end in the various stages of the welding process. What is meant by this is maintaining a constant value of velocity of the ends of the belt in the various stages of the process and implementing the specified displacements by the working units of the device.

A prototype of an automated welding machine using this process control method has been developed [43] taking into account technical and utilitarian conditions in industrial practice (Fig. 1). In consequence, the main features of the designed machine are as follows:
- controlling the length of the belt at each of the process stages to obtain the precisely defined final length of the belt,

- using mostly the electrical components, rather than pneumatic drives,

- maximal simplification of the construction, using as few measurement components as possible.

Due to these assumptions, the main principle of the designed automatic welder consists of controlling the position and velocity of the movable belt gripper (2a), which has one end of the belt (1) clamped. This part is driven by a power screw mechanism and it is responsible for making the required displacement of the end of the belt and pressure to

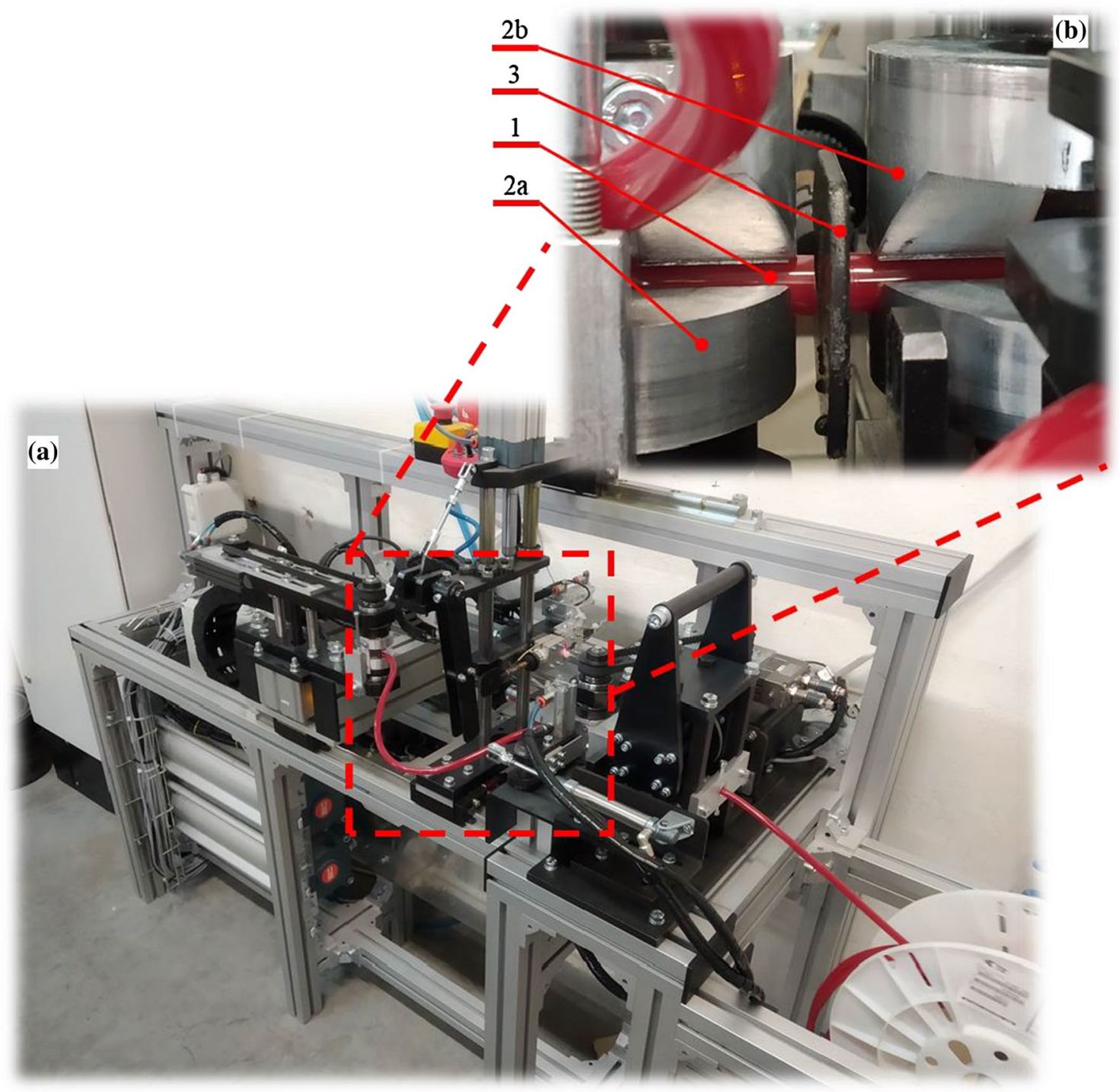

Fig. 1 The prototype of the automated hot plate welder which was introduced to industrial production of the belts; a the whole device during the belt dosage process, $\mathbf{b}$ the focused view to the welding unit during plasticizing of the belt: 1 -belt, $2 \mathrm{a}$-movable belt gripper, $2 \mathrm{~b}$ - fixed belt gripper, 3-hot plate 
the hot plate (3). From the other side, the hot plate (3) is also driven by the same mechanism, but with a velocity that is two times lower. So, in this case, simultaneous movement of the movable gripper and the hot plate, with different velocities, can be obtained. This phenomenon allows obtaining pressure from the hot plate to the second end of the belt (1) which is clamped by a fixed belt gripper (2b). Therefore, simultaneous pressure between the ends of the belt and hot plate during the plasticizing process can be obtained. This action is controlled only by displacement or velocity. The same situation is during the pressing stage when the hot plate is retracted.

This approach makes it possible to obtain the main functional features as per the customer requirements:

- obtaining the precise value of the length of belt due to displacement control,

- simplifying the structure of the control system and device design, as only one drive unit is used also for hot plate and belt displacement,

- exclusion of the possibility of the lack of precision in controlling the welding process, which could occur during controlling of the small-value forces in case of the pressure-controlled system. This phenomenon can occur due to some value of measurement system errors, which can have a big percentage influence in the case of small forces value,

- elimination of the stick-slip effect, which could occur in the presumed pneumatic drive system, in case of small inlet pressure (in case of small required forces).

In this case, in contrast to the classic approach $[19,44]$, where the welding process is divided into 5 phases characterized by the fact that the individual operations include control of the pressing force (or pressure), a new method of process handling based on speed and displacement control was proposed for the description of belt welding, while the overall process was simplified to 4 phases (Fig. 2).

During the first stage-plasticizing of the belt (Fig. 2a), the hot plate (3) is pressed against the end of the belt (1b) mounted in the fixed jaw (2b), as a result of the plate (3) moving at controlled velocity $v_{\mathrm{pl}}$ towards this part of the belt. At the same time, the other end of the belt (1a), mounted in the movable jaw (2a), is pressed against the hot plate (3) from the other side, as a result of its velocity relative to the fixed end (1a) being $2 \times v_{\mathrm{pl}}$, while this value relative to the hot plate (3) is $v_{\mathrm{pl}}$. This ensures that both ends of the belt are evenly pressed against the hot plate during the plasticizing process. However, it should be noted that the value of the plasticizing force $F_{\mathrm{pl}}$ is a variable value, not known and not regulated. Its value depends on the type of material and actual temperature state, which has influence on the obtained force $F_{\mathrm{pl}}$ value.
The application of the flat front surface of the belt (1a and $1 \mathrm{~b}$ ) to the hot plate (3) causes a non-linear increase in its temperature along the axis [45]. In this phase, the flash is formed, as a result of early plasticizing and melting of the belt (1a and $1 \mathrm{~b}$ ) on the hot plate (3). Partial melting of the surface causes the surface of the belt ends (1a and 1b) to match the flat surface of the plate (3). This converts the localized heat conduction between the hot plate and the vertices of the belt end surface irregularities into a contact conduction present on the entire surface. This improves the efficiency of the heating process and has a positive effect on the quality of the connection, since the parallel alignment of the interconnected belt surfaces is ensured (Fig. 2a) [1].

When plasticizing the end of the belt $(1 \mathrm{a}$ and $1 \mathrm{~b})$ on a hot plate (3), physical phenomena associated with heat exchange can be observed: conduction, convection and radiation [18, 19, 27, 29, 43-45]. Taking into account the individual heat fluxes, one can distinguish (Fig. 2a):

- heat $Q_{\mathrm{p} 3-1}$ transferred from the hot plate (3) to the belt surface (1a and $1 \mathrm{~b}$ ) via contact conduction,

- heat $Q_{\mathrm{p} 1}$ conducted inside the belt material (1a and $1 \mathrm{~b}$ ),

- heat $Q_{\mathrm{c} 3}$ transferred from the hot plate (3) to the belt (1a and $1 \mathrm{~b}$ ) by convection,

- heat $Q_{\mathrm{r} 3}$ transferred from the hot plate (3) to the belt (1a and $1 \mathrm{~b}$ ) by radiation,

- heat $Q_{\mathrm{c} 1}$ transferred by the outer cylindrical surface of the belt (1a and $1 \mathrm{~b}$ ) to the environment by convection,

- heat $Q_{\mathrm{r} 1}$ transferred by the outer cylindrical surface of the belt ( $1 \mathrm{a}$ and $1 \mathrm{~b}$ ) to the environment by radiation.

In this case, the dominant modes of heat exchange that have an obvious effect on the increase in belt temperature are: contact conduction $\left(Q_{\mathrm{p} 3-1}\right)$ between the hot plate (3) and the belt ( $1 \mathrm{a}$ and $1 \mathrm{~b})$ and thermal conduction $\left(Q_{\mathrm{p} 1}\right)$ inside the belt material (1a and 1b). The thermal radiation $\left(Q_{\mathrm{r} 3} \mathrm{i} Q_{r 1}\right)$ is not as significant as the conduction $\left(Q_{\mathrm{p} 3-1}\right.$ i $\left.Q_{\mathrm{p} 1}\right)$ because the process temperature is relatively low and usually does not exceed $300{ }^{\circ} \mathrm{C}[3,43]$. Therefore, it is possible to distinguish two characteristic geometric dimensions:

- length $p$ at which the temperature of the belt in its central axis exceeds the welding temperature $T_{\mathrm{w}}$ (the temperature at which the material is plasticized and ready to form a permanent joint),

- the length $h$ at which the temperature in the central axis of the belt exceeds the environment temperature $T_{0}$.

In the phase of removing the heating device from the welding area (Fig. 2b), the hot plate (3 in Fig. 2a) being removed from the area between the ends of the belt ( $1 \mathrm{a}$ and 1b). At this stage, the heating process of the belt ends is completed, and at the same time, the effect of cooling them 
(a) Plasticizing

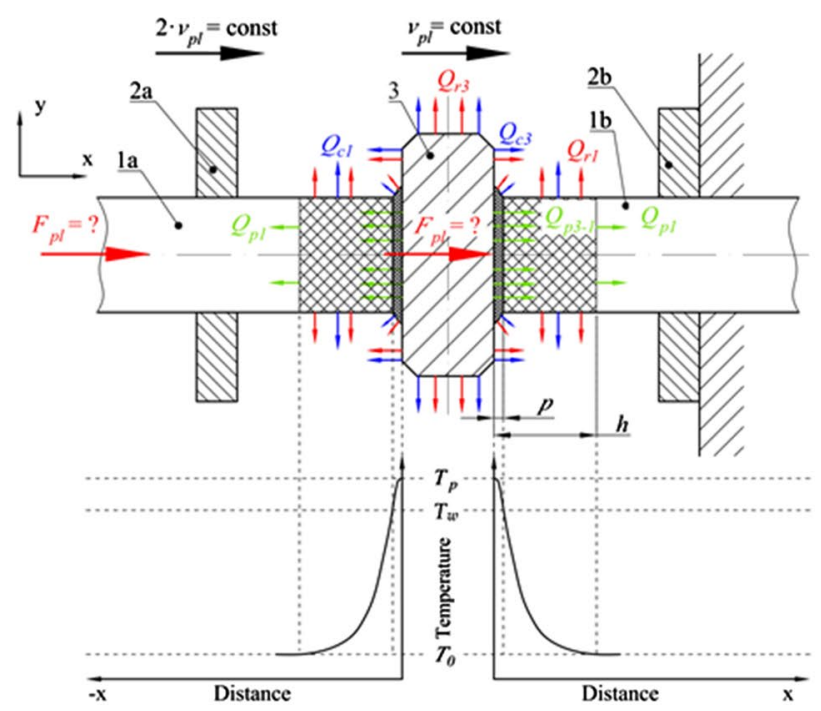

(c) Pressing

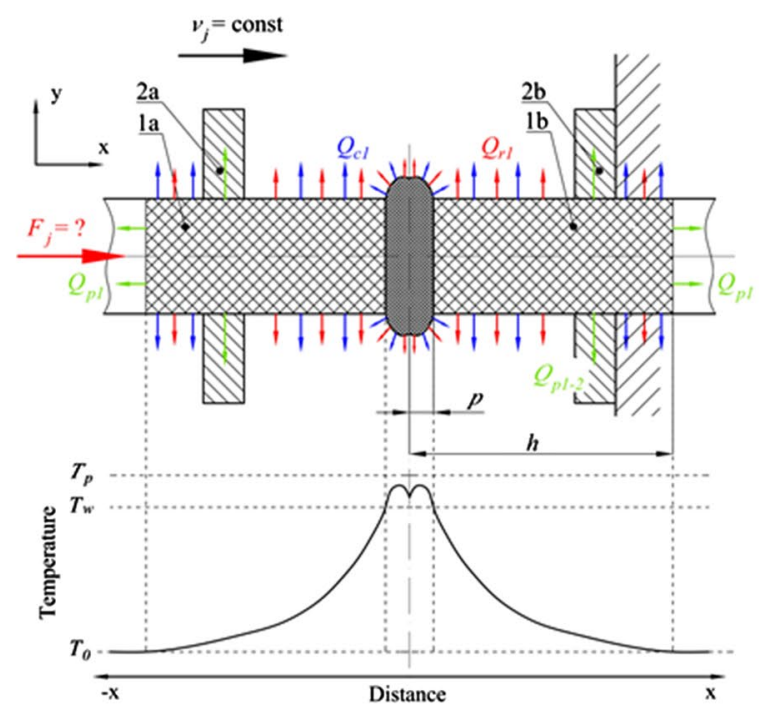

Fig. 2 Diagram of the hot plate welding process of the drive belt divided into 4 phases and marked by the expected temperature distribution in the belt axis: $1 \mathrm{a}-$ movable end of the belt, $1 \mathrm{~b}$ - fixed end of the belt, $2 \mathrm{a}$-movable belt holder, $2 \mathrm{~b}$-fixed belt holder, 3 -hot plate; $v_{p l}$ velocity of belt material plasticization, $v_{j}$ velocity of pressure during joining, $v_{c}$ velocity of pressure during cooling, $F_{p l}$ pressure force during belt plasticization, $F_{j}$ pressure force when connecting the belt ends, $F_{c}$ pressure force during cooling of the connection, $T_{p}$ temperature of the hot plate, $T_{w}$ welding temperature, $T_{0}$ environ-

as a result of the influence of the gas surrounding them is noticeable. It is important that the temperature of their flat surfaces does not decrease to a level lower than the welding temperature of $T_{\mathrm{w}}$. Therefore, taking into account a certain non-zero time needed to remove the hot plate (3), (b) Switch-over

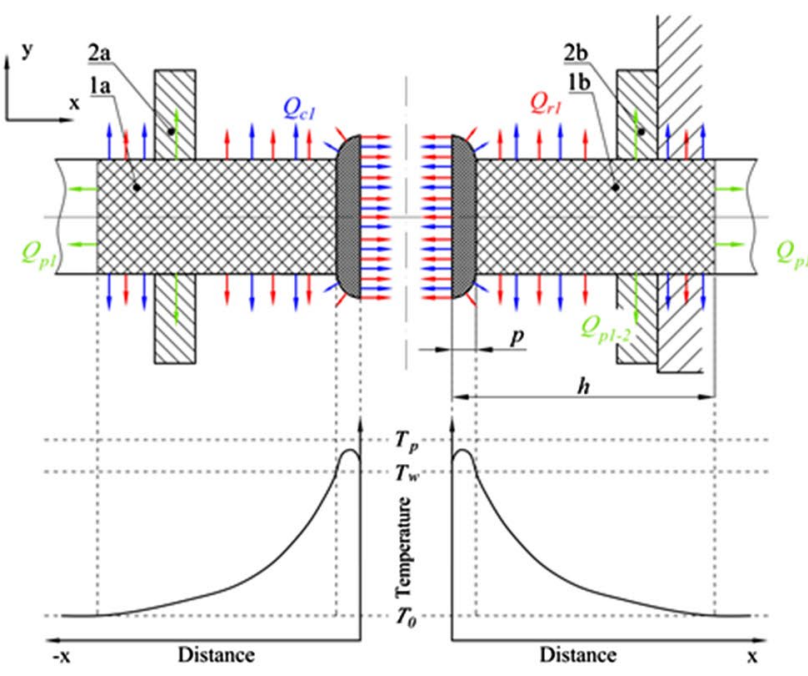

(d) Cooling

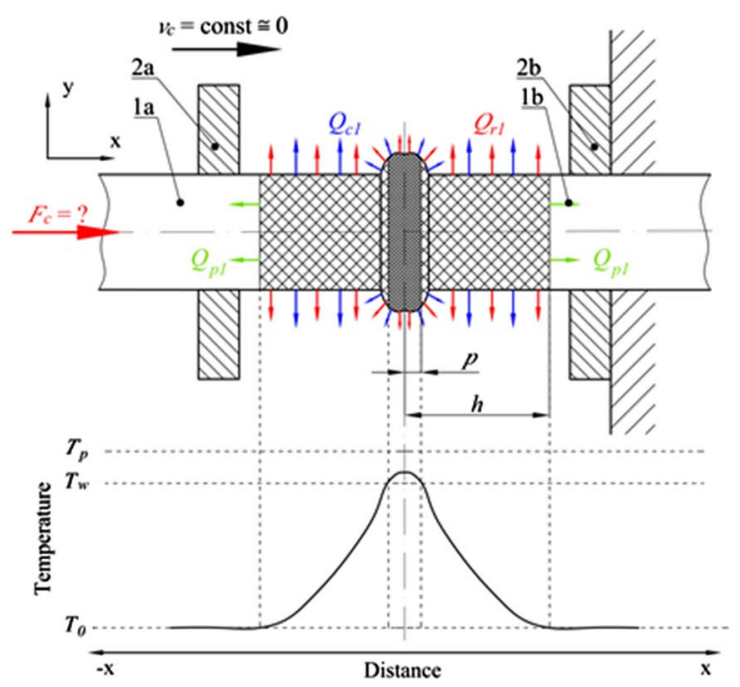

ment temperature, $p$ belt plasticizing distance, $h$ section heated to a temperature higher than environment temperature; $Q_{p 3-1}$ heat conduction between the hot plate and the belt, $Q_{p 1-2}$ heat conduction between the belt and the holder, $Q_{p 1}$ heat conduction inside of the material, $Q_{r 1}$ heat transmitted to the environment from the belt by radiation, $Q_{r 3}$ heat transmitted to the environment from the hot plate by radiation, $Q_{\mathrm{c} 1}$ heat transmitted to the environment from the belt by convection, $Q_{\mathrm{c} 3}$ heat transmitted to the environment from the hot plate by convection

the temperature of the hot plate $T_{\mathrm{p}}$, is slightly higher than the required welding temperature $T_{\mathrm{w}}$.

In the pressing phase (Fig. 2c), the movable end of the belt (1a) is pressed against the fixed one (1b) at velocity $v_{j}$ to obtain a connection. As a result of the fact that the only 
parameter controlled in this case is the velocity $v_{j}$, the value of the compressive force $F_{j}$ is unknown and unregulated. The course of this phase is extremely important for the correctness of the entire welding process, since the interactions between the ends of the belt begin there:

- chemical reactions between polymer macromolecules,

- mechanical interactions between macromolecules, consisting in their splicing, which facilitates the occurrence of chemical reactions [6].

In the connection cooling phase (Fig. 2d) the movable end of the belt (1a) does not move relative to the fixed one (1b), velocity of the compression $v_{\mathrm{c}} \cong 0$. However, it should be noted that the belt ends ( $1 \mathrm{a}$ and $1 \mathrm{~b}$ ) are pressed together by the residual force $F_{\mathrm{c}}$ remaining after the compression process (Fig. 2c). During this phase (Fig. 2d), the connection cools down, as a result of heat exchange with the environment. Ideally, the connection should be kept in this state for a period of time allowing its temperature to be lowered to $T_{0}$. The main assumptions of this phase are:

- the temperature of the belt and the connection is equalized due to thermal conductivity in the material structure (heat $Q_{\mathrm{p} 1}$ ),

- chemical reactions and mechanical interactions between macromolecules continue,

- cooling of the connection occurs as a result of heat exchange with the environment by convection $\left(Q_{\mathrm{c} 1}\right)$ and radiation $\left(Q_{\mathrm{r} 1}\right)$.

After cooling, the connected belt can be further processed, for example by removing the flash.

Compared to the classic description of the welding process $[19,44]$, the modified welding process is characterized by the fact that in the removal phase of the heating device (Fig. 2b), the belt ends (1a and $1 \mathrm{~b}$ ) are not far away from the hot plate (3). It is retracted during its contact with the belt material, which provides improved energy efficiency. The plate is covered with the material that provides a low coefficient of friction in combination with the plasticized material. Additionally, during cooling of the connection (Fig. 2d) velocity of movement of the movable end of the belt (1a) $v_{\mathrm{c}} \cong 0$. Therefore, the external force causing compression during cooling ( $F_{\mathrm{c}}$ in Fig. $2 \mathrm{~d}$ ) is also close to zero. This phenomenon is purposeful, taking into account the high susceptibility of the belt to buckling - as a result of which a not completely cooled joint can be damaged.

The analysis of the hot plate welding process points out that from the solid mechanic's point of view, the main physical phenomenon that occurs during process flow is compression of the material at elevated, but variable temperature. In addition, it should be noted that one of the most important stages of the process is the plasticizing of the belt on the hot plate. The course of this stage determines the course of the rest of the welding process.

The dependence of the controlled velocity can be showed in the process cyclogram (Fig. 3). Contrary to the standard cyclograms from the classical approach to hot plate welding $[19,44]$, the cycle was simplified to four phases. Using this assumption, a change of only one parameter is required, which allows authors to simplify the control system and constructional solutions of the machine.

A review of the state of knowledge of the described welding process also provides information on the lack of a clear approach to modeling the welding process in terms of the constant movement velocity during these technological operations. In addition, in all analyzed publications, the complex model of the hot plate welding operation, in the sense of dependency between process parameters, e.g.:

- forces,

- velocities,

- temperature,

- time, etc.

is not present. The research carried out so far focuses on plasticizing under conditions of a certain-adjustable pressing force, rather than displacement, and they are focused only on chosen aspects (e.g., temperature distribution, stress
Fig. 3 Cyclogram of the hot plate welding process in designed welder: I-plasticizing, II-switch over, III- pressing, IV-cooling of the weld, $v_{p l}$ velocity of belt material plasticization, $v_{j}$ velocity of pressure during joining

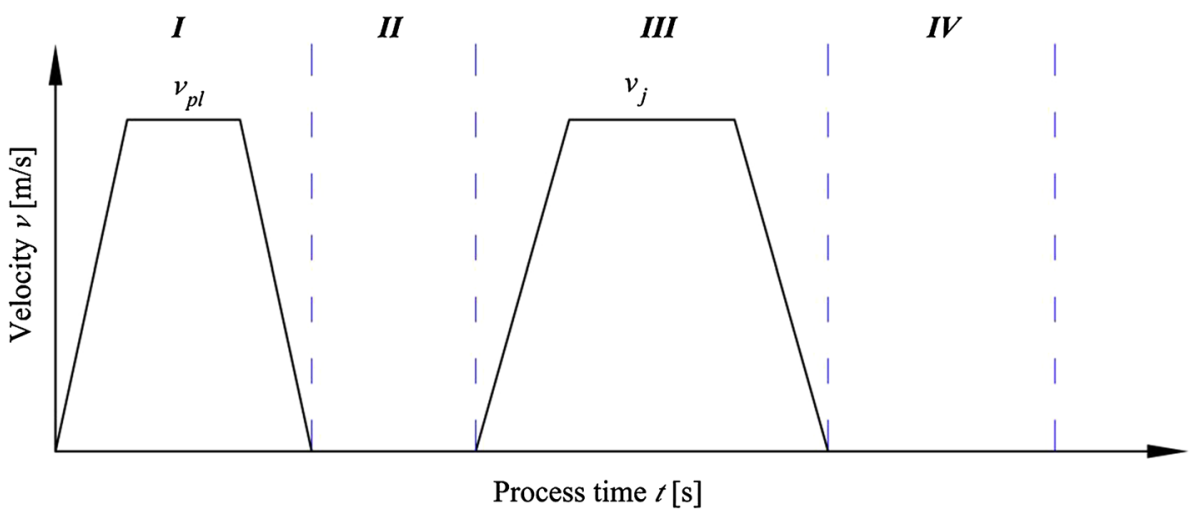


cracking, contact thermal resistance, etc.). It is, therefore, advisable to develop a mathematical model, in particular of the process of belt plasticizing under conditions of adjustable velocity and displacement.

\subsection{Material conditions}

Drive belts with a circular cross section are usually made of thermoplastic elastomers $[1,3]$. They belong to a group of materials that can be subjected to very large deformations and after being unloaded they return to their original shapes [46]. One of the most commonly used materials in drive belts is a thermoplastic elastomer based on polyurethane. For further analysis, the material with the trade mark TPU C85A [3], which is a case study in the analysis of hot plate welding of drive belts, was adopted.

In general, polyurethanes have a segmented structure (Fig. 4). Their hydrocarbon chain consists of alternating flexible segments (2): methylene, ester or ether, as well as rigid segments (1): urea, urethane or aromatic. Rigid segments give the material high values of strength parameters. Flexible ones, on the other hand, greatly affect its ability to deform. The segments do not mix with each other, forming a two-phase, heterogeneous structure (Fig. 4) [47].

The macromolecule chains of the polyurethane thermoplastic elastomer are reticulated by means of physical hydrogen and van der Waals forces, which undergo reversible decomposition at elevated temperature. At the basic temperature of use, the material exhibits a highly elastic state, where reversible deformations up to several hundred percent caused by relatively small loads result from the possibility of stretching the chains of macromolecules under the influence of load. Such properties of the structural network of this type of polyurethane cause that on a macroscopic scale this material exhibits properties from the intersection of elastomeric and thermoplastic plastics, which allows its repeated thermal processing, including extrusion, injection or welding [48].

A number of studies have already been carried out on polyurethane thermoplastic elastomers in order to determine their mechanical characteristics. Qi [49] and Boyce [50] conducted research on these materials to formulate their constitutive model, taking into account the elastic hysteresis loop

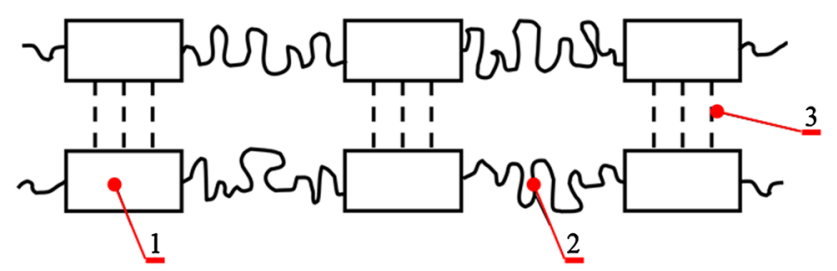

Fig. 4 Example structure of polyurethanes [47]: 1—rigid segment, 2-flexible segment, 3-crosslinking during cyclic deformation. Similar work was carried out by Kukla [51], Drozdov [52] and Wang [53]. This work is based on the analysis of elastic strain energy, which is typical for models of hyperelastic materials, but does not take into account the deformation at elevated temperature. Diani [54] described the elastic deformation of thermoplastic elastomers in a novel way, but also based on models of hyperelastic deformations. Das [55] developed a constitutive model based on the temperatures of two characteristic thermodynamic points for rubber-like materials. Eberlein [56] described the properties of the polyurethane thermoplastic elastomer TPU with a model of a non-linearly elastic-plastic material, but only in the range of standard environment temperature. Henze [57] and Yildrim [58], focused in turn on the description of the mechanical properties of TPU, in the context of modifying its microstructure. However, little information can be found on the description of the properties of the final product-drive belts. Krawiec [59] conducted research on the distribution of temperature influence on the thermal distribution of polyurethane V-belts, but these studies do not provide information on their mechanical behavior under compression conditions at elevated temperature.

In view of the unsatisfactory results of the review of the state of knowledge, the authors have undertaken research activities to determine the selected thermomechanical properties of the welded belt material and its reaction to heating. Based on their results, the following conclusions can be drawn in terms of the phenomena occurring during hot plate welding, and in particular the process of plasticizing the material:

- the material does not show a clear melting point, its behavior at elevated temperature is similar to that of amorphous bodies. As a result, it is not possible to indicate a clear plasticizing temperature [60],

- heating the belt with a hot plate is a transient process [45],

- the material exhibits strongly non-linear characteristics of the stress response to forcing in the form of longitudinal or transverse deformation [61, 62].

These conclusions are the basis for modeling the process of belt plasticizing on the hot plate in order to estimate the effective displacement velocity of the belt end relative to the hot plate. With this information, it is reasonable to undertake research activities and refine what is known about the thermomechanical properties of this material in the context of modeling the developed welding methodology.

\subsection{An approach to modeling the plasticizing process}

Developing the mathematical model of this operation is required to develop a set of parameters for the control 
system. To prepare the mathematical model of the plasticizing process, it is necessary to take into consideration the following facts:

- the welded material has specific properties, which is shown by the features from the borderline of elastomers and thermoplastics $[46,47]$. That is why during the preparation of the mathematical model it is necessary to take into account both elastic and viscous behavior during the compression. It should be noted that these features are also strictly connected with plasticizing velocity,

- compression during the plasticizing operation is carried out at an elevated temperature, where the temperature distribution is a function of technological parameters. This phenomenon causes local changes in the properties of the material. What is more, the values of process temperature exceeds the phase change temperature, so the influence of the temperature on the behavior of the material can be very high. Its observable effect is that the mechanical response for axial forces (which are present during plasticizing) can vary very gradually during the process flow.

To consider these facts during the modeling of the plasticizing process, the authors decided to use the combination of basic material models: Newton's and Hooke's [63-65]. This approach allows for considering viscoelastic behavior of the material. Using these elementary components, the Kelvin-Voigt model can be built. Contrary to the simpler situations (e.g., during modeling the properties of material which works at room temperature), for the plasticizing operation, the authors decided to prepare a model with controlled parameters (Fig. 5).

The most characteristic feature of this proposed approach to model the plasticizing parameters is the fact, that the elastic parameter (modulus of proportionality $E$ ) and the viscous parameter (dynamic viscosity $\eta$ ) will depend on the temperature of the material. Additionally, the ratio between these two properties, which can be described by an additional parameter $k$, also depends on the temperature. In the authors'

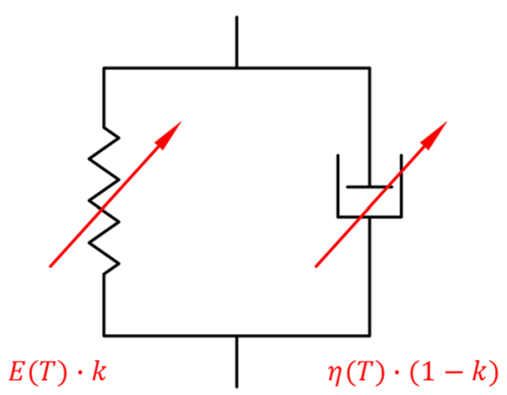

Fig. 5 Kelvin-Voigt model with controlled parameters opinion, this approach can imitate the material behavior at changed and elevated temperature in a good way (where material at room temperature shows the domination of the elastic properties, but at melting temperature the viscous one dominates). The assumed model can be described by the following formula (1):

$\sigma(t)=k \times E(T) \times \varepsilon+(1-k) \times \eta(T) \times \dot{\varepsilon}$,

where $\sigma$ is the stress, $E$ is the modulus of proportionality, $\varepsilon$ is the strain, $\eta$ is the dynamic viscosity, $\dot{\varepsilon}$ is the strain rate, $k$ is the coefficient of proportionality between the elastic and the viscous component, which can be described by the function (2):

$k=f(T(x))$,

where $T$ is the temperature, $x$ is the distance from the hot plate, measured along the axis of the belt (Fig. 2).

To properly describe the planned plasticizing model, considering the current state of knowledge (especially the issue of material features), it is necessary to make a series of thermomechanical tests of the properties connected with the plasticizing operation.

As a result, the following tests were planned:

- the compression test of the belts at elevated temperature to obtain the proportionality modulus $E_{\mathrm{c}}$,

- the dynamic thermomechanical analysis for evaluation of the dynamic $\eta$ viscosity parameter, which makes it possible to fulfill and calculate the mathematical model, and

- the designation of the plasticizing force $F_{\mathrm{pl}}$ as a function of time $t$ or displacement $s$ at a constant plasticizing velocity $v_{\mathrm{pl}}$,

which makes it possible to obtain the verifiable parameter for the model derivation.

\section{Research methods}

\subsection{Belt compression tests at elevated temperature}

First of all, axial compression of cylindrical samples of the drive belt material was tested at two values of the compression velocity $v_{\mathrm{c}}$ at a variable temperature $T$. The tests were carried out on the MTS Insight 50 strength testing machine, with a built-in climatic chamber (Fig. 6).

Compression tests were performed to determine the compressive stresses $\sigma_{\mathrm{c}}$ in the function of deformation $\varepsilon_{\mathrm{c}}$, depending on the temperature $T$ and the compressive velocity $v_{\mathrm{c}}$. Prior to testing, the samples were conditioned in a climatic chamber, in which a compression test was then 

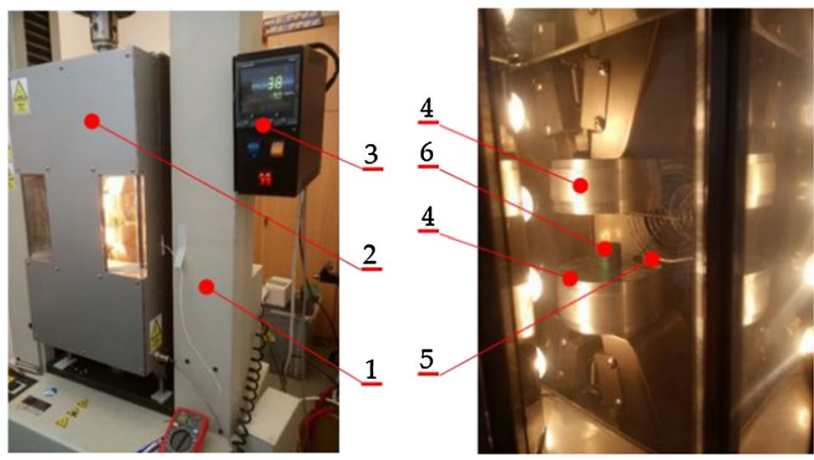

Fig. 6 The workstation for testing thermomechanical properties of drive belts with MTS Insight 50 strength testing machine and climatic chamber during testing: 1-strength testing machine, 2-climatic chamber, 3-climatic chamber controller, 4-compression grips, 5temperature sensor, 6-specimen before test

performed to equalize the temperature throughout the volume. Two groups of parameters were tested (Table 1), the values of which were selected on the basis of standards PN-EN ISO 604 and PN-80/C-04246. 5 testing cycles were performed for all parameters. The graphs with the correlation between the compressive stress $\sigma_{\mathrm{c}}$ and the deformation $\varepsilon_{\mathrm{c}}$ were recorded.

A compression plate was used for testing (Fig. 7), equipped with a cylindrical notch with a diameter of $25 \mathrm{~mm}$ and a depth of $1 \mathrm{~mm}$, which prevented the slippage of the specimens, without hampering the deformation of their side surfaces. The front surfaces of the specimens were wetted with silicone grease designed to operate at temperatures up to $200{ }^{\circ} \mathrm{C}$. This maintains the axial stress state of the specimens during compression.

\subsection{Determination of dynamic viscosity of the belt material}

The dynamic thermomechanical analysis of DMTA was then tested on the Anton Paar MCR302 rotary rheometer. For testing, specimens were taken from the belt with a circular cross section and a diameter of $d=18 \mathrm{~mm}$, subjected to machining to the form of rectangular beams with dimensions $53.50 \pm 0.31 \times 10.21 \pm 0.20 \times 3.74 \pm 0.33 \mathrm{~mm}$.

The testing method consisted in introducing the orthogonal beams in controlled oscillations, by inflicting torsioninducing deformations, under varying temperature conditions. The temperature $T$ change cycle included a single heating. A similar methodology was used commonly in research work concerning thermoplastic materials properties. One example is research on self-healing on polyurethane elastomers [66], which depends on manipulation on hydrogen bonds. The DMTA methodology was used for the verification of thermomechanical properties of the material, especially for glass transition temperature. Another example of using the DMTA test for the evaluation of polymeric properties was conducted for modified thermoplastic material [67] when damping factor from DMTA test was used for evaluation of the changes obtained by modification. Test results, especially components connected with a modulus
Table 1 Parameters of the belt compression test under variable temperature conditions

\begin{tabular}{lll}
\hline Parameter & Designation & Value \\
\hline Specimen diameter & $d[\mathrm{~mm}]$ & $18 \pm 0.2$ \\
Specimen height & $h[\mathrm{~mm}]$ & $20 \pm 0.5$ \\
Testing velocity & $v_{\mathrm{c}}[\mathrm{mm} / \mathrm{min}]$ & $1 ; 10$ \\
Specimen temperature & $T\left[{ }^{\circ} \mathrm{C}\right]$ & $25 \pm 1 ; 40 \pm 1 ; 55 \pm 1 ; 70 \pm 1 ; 85 \pm 1 ;$ \\
& & $100 \pm 2,125 \pm 2 ; 150 \pm 2 ; 175 \pm 2 ;$ \\
Test termination limit & $\varepsilon_{\max }[\%]$ & $200 \pm 2$ \\
\hline
\end{tabular}

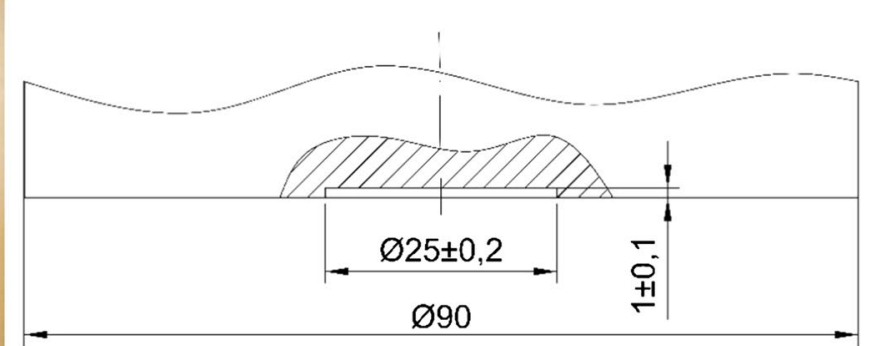

Fig. 7 Compression plate with the most important cylindrical notch dimensions 
of elasticity $G$ and damping factor $\delta$ allows designating the dynamic viscosity [65]. Its value will be necessary to develop the planned model of plasticizing the belts during hot plate welding.

The study had the following assumptions:

- temperature range from $-30{ }^{\circ} \mathrm{C}$ to $+180{ }^{\circ} \mathrm{C}$, recorded continuously,

- velocity of temperature change $|\nabla T|=+5^{\circ} \mathrm{C} / \mathrm{min} \mid$ nabla $|\nabla T|=+5^{\circ} \mathrm{C} / \mathrm{min}$

- oscillation amplitude $A=0.02 \%$,

- oscillation frequency $f=1 \mathrm{~Hz}$.

The measuring system of the device recorded the response of the sample to the forced oscillations and the current temperature conditions. Based on the obtained results, the dynamic viscosity $\eta$ at torsional loads was determined.

\subsection{Empirical verification of the plasticizing process}

The last of the performed tests consisted of axial plasticizing of the belt end on a hot plate, under conditions that simulate industrial welding of belts. The main assumption of the tests was a constant velocity of the belt movement relative to the heating device $v_{\mathrm{pl}}$, over the entire range of plasticizing time $t$, with the tests being carried out at its different values. The tests were performed on the MTS Insight $50 \mathrm{kN}$ strength testing machine (Fig. 8), whose jaw (1) and handle (2) pressed the end of the belt (3) against the heating plate (4). This element (4) was heated using Multi-TC, the $70 \mathrm{~W}$ electric welding machine for drive belts, manufactured by BEHABelt. The plate (4) had its lower surface adjoining to the thermal insulation pad (5), made of a ceramic plate.

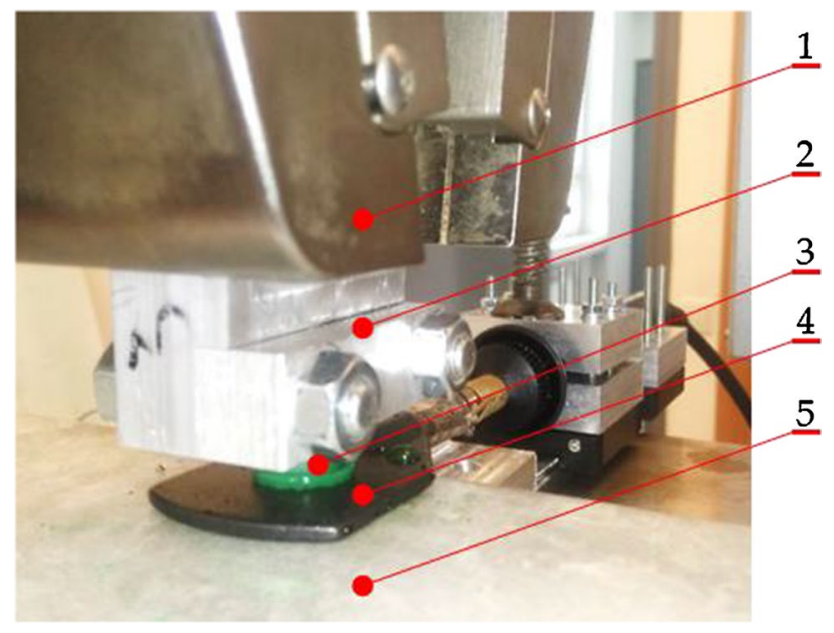

Fig. 8 View of the workstation during the test: 1 -jaw of the MTS strength testing machine, 2-specimen grip, 3-specimen, 4-heating device with the hot plate, 5-thermal insulation pad.
Each time a calibration (I) was performed before the measurement (Fig. 9), which consisted in the fact that a sample of the belt (1) with a height $h$ (the free end of which extends from the grip to a distance $h_{1}$ ) and a diameter $d$, mounted in the grip (2), was moved with a constant velocity $v_{i}$ towards the thermal insulation plate (5) with a constant thickness $t=0.5 \mathrm{~mm}$, until physical contact (detected by the strength measurement system of the testing machine). The plate (5) was adjacent to the hot plate (3) lying on the ceramic pad (4). The traverse movement was then stopped and the plate (5) removed.

Next, the actual testing (II) was started, in which the belt was pressed against the hot plate at the working velocity $v_{\mathrm{pl}}$, while simultaneously measuring: the displacement $s$ of the traverse of the testing machine, plasticizing time $t$, the pressing force $F_{\mathrm{pl}}$ and the temperature value of the hot plate $T_{\mathrm{p}}$. 50 testing cycles were made for: 5 velocities of belt to plate pressure $v_{\mathrm{pl}}$ and two specimen diameters $d$. Plasticizing was carried out in a range far exceeding the actual deformation during welding - up to $50 \%$ of the length of the free end $h_{1}$. The parameters of the performed tests are listed in Table 2 (see Fig. 9).

The introduction of the calibration phase (I) made it possible to compensate for the inaccuracy of the specimen height dimension $h$. The use of a thermal insulating spacer limited the convection heating of the specimen in the calibration phase before the actual testing was started.

\section{Results}

\subsection{Belt material compression}

Average stress-strain curves $\left(\sigma_{\mathrm{c}}-\varepsilon_{\mathrm{c}}\right)$, for belt compression tests with a belt diameter $d=18 \mathrm{~mm}$, at temperature $T(25$, $\left.40,55,70,85,100,125,150,175\left[{ }^{\circ} \mathrm{C}\right]\right)$, with two velocities: $v_{\mathrm{c} 1}=1 \mathrm{~mm} / \mathrm{min}$ and $v_{\mathrm{c} 10}=10 \mathrm{~mm} / \mathrm{min}$, performed to a strain of $\varepsilon_{\max }=30 \%$ are shown in Fig. 10 .

Analyzing the course of the compression curves $\left(\sigma_{\mathrm{c}}-\varepsilon_{\mathrm{c}}\right)$ as a function of the temperature $T$, the expected effect of a decrease in the compressive stress $\sigma_{\mathrm{c}}$ was observed with an increase in the specimen temperature $T$. Regardless of the

Table 2 Belt plasticizing test parameters

\begin{tabular}{lll}
\hline Parameter & Designation & Value \\
\hline Belt diameter & $d[\mathrm{~mm}]$ & 12,18 \\
Testing velocity & $v_{\mathrm{pl}}[\mathrm{mm} / \mathrm{min}]$ & $2,4,8,12,16$ \\
Hot plate temperature & $T_{\mathrm{p}}\left[{ }^{\circ} \mathrm{C}\right]$ & $300 \pm 1$ \\
Specimen height & $h[\mathrm{~mm}]$ & $25 \pm 0.1$ \\
Removing the specimen from the grip & $h_{1}[\mathrm{~mm}]$ & $10 \pm 0.1$ \\
Maximum specimen displacement & $s[\mathrm{~mm}]$ & 5.5 \\
\hline
\end{tabular}


Fig. 9 Diagram of the workstation for pressing the belt to the hot plate: I-calibration phase, II- actual testing phase; 1 belt specimen, 2-grip, 3-hot plate, 4-thermal insulation pad, 5-thermal insulation spacer, $v_{i}$ initial calibration speed, $v_{p l}$ testing velocity

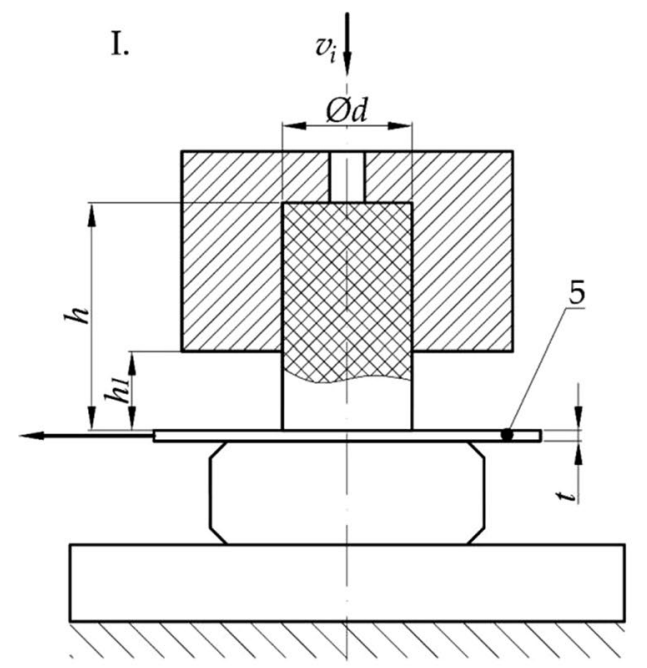

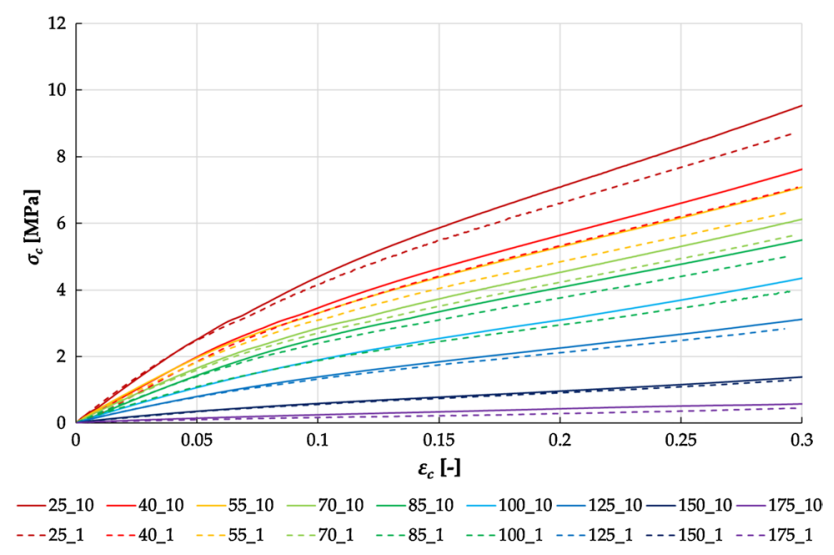

Fig. 10 Sample compression curve diagrams (stress $\sigma_{\mathrm{c}}-$ strain $\varepsilon_{\mathrm{c}}$ ) for: compression velocities $v_{\mathrm{c} 1}=1 \mathrm{~mm} / \mathrm{min}$ and $v_{\mathrm{c} 10}=10 \mathrm{~mm} / \mathrm{min}$ for strain limit $\varepsilon_{\max } 30 \%$ at temperature $T(25,40,55,70,85,100,125$, 150 and $\left.175\left[{ }^{\circ} \mathrm{C}\right]\right)$

temperature $T$, in the studied deformation range $\left(\varepsilon_{\max }=30 \%\right)$, the compression curve $\left(\sigma_{\mathrm{c}}-\varepsilon_{\mathrm{c}}\right)$ exhibits a nonlinear, degressive character, regardless of the compression velocity $v_{\mathrm{c}}$. However, it should be noted that in the initial characteristic range $\left(\sigma_{\mathrm{c}}-\varepsilon_{\mathrm{c}}\right)$, at a strain $\varepsilon_{\mathrm{c}}$ not exceeding $5 \%$, a linear segment can be distinguished, indicating a proportional change in the compressive stresses $\sigma_{\mathrm{c}}$ with the strain $\varepsilon_{\mathrm{c}}$. This phenomenon occurs independent of the temperature $T$ of the compressed specimen and the compressive velocity $v_{\mathrm{c}}$.

\subsection{Determination of material viscosity}

Based on the DMTA analysis, the average values of the individual components of the transverse modulus of elasticity were determined: the storage modulus $G_{\text {avg }}^{\prime}$ and the loss

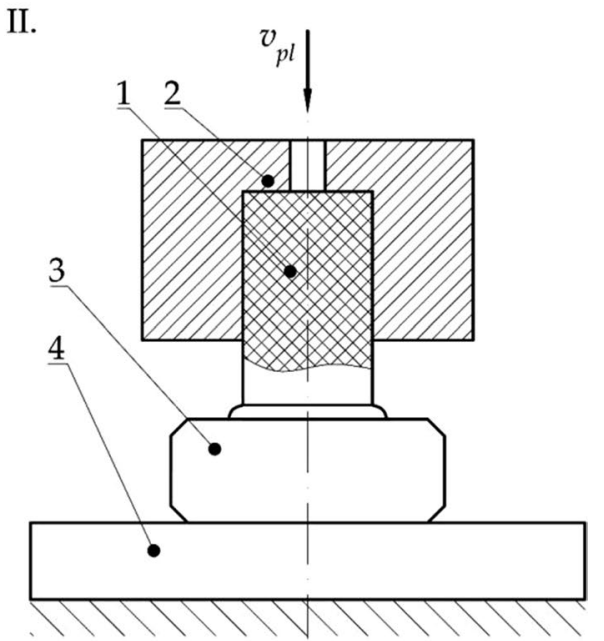

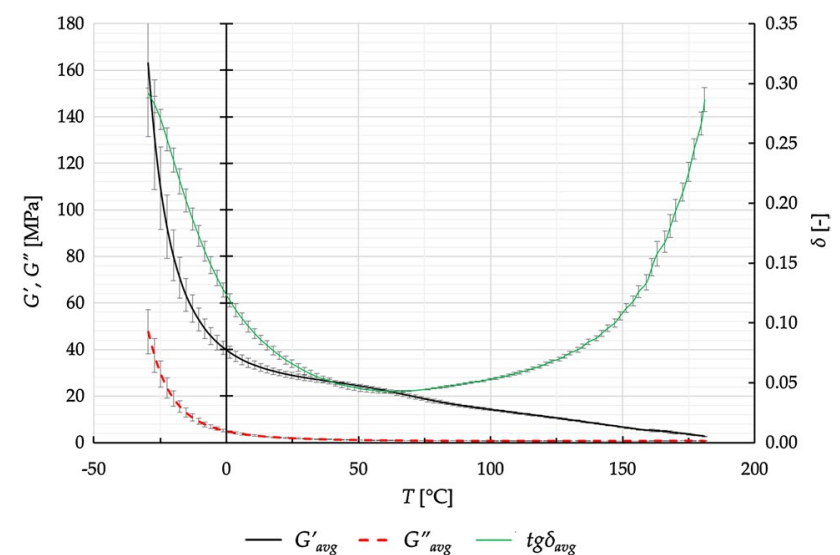

Fig. 11 Characteristics of the components of the transverse modulus of elasticity $G$ : the storage modulus $G_{\text {avg }}^{\prime}$ and the loss modulus $G_{\mathrm{avg}}^{\prime \prime}$, as well as the loss factor $\operatorname{tg} \delta_{\text {avg }}$ depending on the material temperature $T$

modulus $G_{\text {avg }}^{\prime \prime}$, as well as the loss factor $\operatorname{tg} \delta_{\text {avg }}$ depending on the temperature $T$ of the material (Fig. 11).

\subsection{Plasticizing material on the hot plate}

The result of the tests of plasticizing the belt on the hot plate belt are the characteristics of the plasticizing force $F_{\mathrm{pl}}$, depending on the displacement of the belt end $s$ and plasticizing time $t$ (Fig. 12).

Analyzing the obtained results, it can be observed that the characteristics of the plasticizing force value $F_{\mathrm{pl}}$, depending on the displacement of the belt end $s$ or time $T$, demonstrate a variable course, whereas the character of the variability is repeated for all tests. In the first part of the characteristics (I), the course of the plasticizing force $F_{\mathrm{pl}}$ is almost constant, and its value is relatively small in comparison with the value 


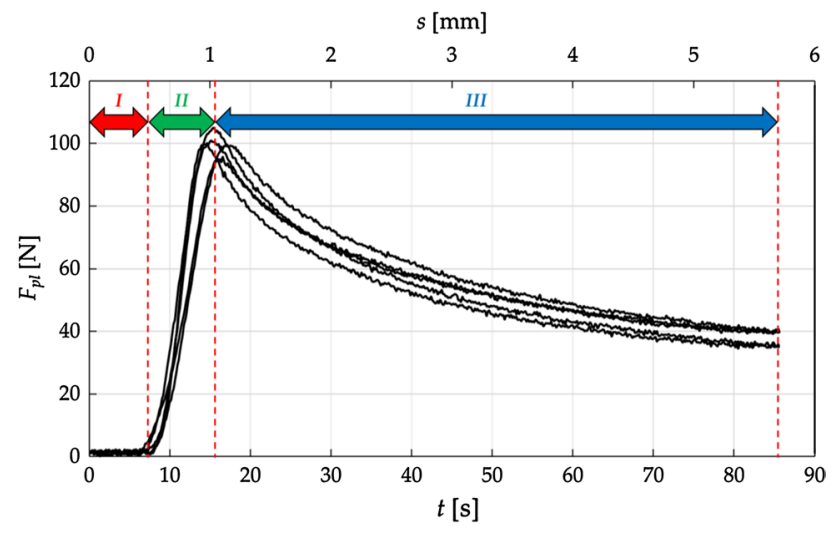

Fig. 12 Characteristics of the belt plasticizing force $F_{\mathrm{pl}}$ on the hot plate depending on the time $t$ and the displacements of the belt end relative to the hot plate, for the belt with a diameter $d=18 \mathrm{~mm}$ and plasticizing velocity $v_{\mathrm{pl}}=4 \mathrm{~mm} / \mathrm{min}$ : I-eliminating the slack resulting from the use of the insulating pad, II-phase of a clear and repeated increase in plasticizing force $\mathrm{F}_{\mathrm{pl}}$, III-phase of the variable force curve depending on the plasticizing velocity

obtained in the subsequent part of the process (Fig. 12). This phenomenon is associated eliminating the slack between the plasticized specimen ( 1 in Fig. 9), and the hot plate (3 in Fig. 9), after removing the thermal insulation spacer (5 in Fig. 9). Therefore, it should be assumed that this phase of the material plasticizing operation is not relevant in the analysis of the process, and as such can be omitted in further consideration, unlike the other two distinguishable phases (II and III) related to changes in strength depending on the plasticizing parameters (Fig. 12, Tables 3, 4).

Table 3 shows the average characteristics of the process of plasticizing a belt with a diameter $d=12 \mathrm{~mm}$ on a hot plate depending on the velocity of the operation $v_{\mathrm{pl}}$, while Table 4 shows for a belt with a diameter $d=18 \mathrm{~mm}$. In both cases, the first phase $(I)$ related to eliminating the slack at the testing workstation was omitted.

\section{Discussion}

The described results of the experimental studies on the thermomechanical properties of the welded material can be used to estimate the effective plasticizing velocity $v_{\mathrm{pl}}$ of the belt material depending on its geometric dimensions. To this end, it is necessary to carry out the analysis of the obtained results, with a view to establish the correlation between the studied parameters and the process parameters, which will be used in further research work to formulate and validate the mathematical model of the belt plasticizing process.

Compression characteristics of the belt material (Fig. 10), regardless of temperature $T$ and velocity $v_{\mathrm{c}}$ can be approximated by the 4 th degree polynomial function in the following form:

$\sigma_{\mathrm{c}}\left(T, v_{\mathrm{c}}\right)=a_{1} \times \varepsilon_{\mathrm{c}}^{4}+a_{2} \times \varepsilon_{\mathrm{c}}^{3}+a_{3} \times \varepsilon_{\mathrm{c}}^{2}+a_{4} \times \varepsilon_{\mathrm{c}}+a_{5}$,

where $a_{1} \ldots a_{5}$ are constant factors, determined empirically.

Assuming that $a_{5}=0$ (starting point of the characteristic $\sigma_{\mathrm{c}}=0 \mathrm{MPa}$ and $\varepsilon_{\mathrm{c}}=0$ ), it is possible to determine the approximated characteristics, with a correlation coefficient $R^{2}>0.9991$. They were used to compare the compressive stress $\sigma_{\mathrm{c}}$ obtained with the same strain $\varepsilon_{\mathrm{c}}$ over the entire range of compression curves $\left(\varepsilon_{\max }=30 \%\right)$, for the two studied compression velocities $v_{\mathrm{c} 1}=1 \mathrm{~mm} / \mathrm{min}$ and $v_{\mathrm{c} 10}=10 \mathrm{~mm} /$ min. A comparative analysis of these values provided information on the relative difference of compressive stresses $\delta \sigma_{\mathrm{c}}$ for both compressive velocities $v_{\mathrm{c}}$, which was calculated from the following dependency:

$\delta \sigma_{\mathrm{c}}\left(T, \varepsilon_{\mathrm{c}}\right)=\frac{\left|\sigma_{\mathrm{c} 10}-\sigma_{\mathrm{c} 1}\right|}{\sigma_{\mathrm{c} 10}} \times 100 \%$,

where $\sigma_{\mathrm{c} 1}$ is the compressive stress at velocity $v_{\mathrm{c} 1}=1 \mathrm{~mm} /$ $\min , \sigma_{\mathrm{c} 10}$ is the compressive stress at velocity $v_{\mathrm{c} 10}=10 \mathrm{~mm} /$ min. Its results are shown in Fig. 13, in the form of the correlation of the compressive stress difference $\delta \sigma_{\mathrm{c}}$ between the values obtained for both compressive velocities $v_{\mathrm{c}}$, at different temperature values of the specimen $T$.

A change in the compressive velocity $v_{\mathrm{c}}$ results in a difference in compressive stresses $\sigma_{\mathrm{c}}$, not exceeding $10 \%$ over the specimen temperature range $T<175^{\circ} \mathrm{C}$, with compressive stresses $\sigma_{\mathrm{c}}$ assuming higher values for the compressive velocity $v_{\mathrm{c}}=10 \mathrm{~mm} / \mathrm{min}$ (Fig. 10). Thus, it can be concluded that this difference is negligible and in this temperature range, the strength of the material does not depend on the deformation velocity $v_{\mathrm{c}}$.

This characteristic is somewhat different (Fig. 13) for the maximum specimen temperature $\left(T=175^{\circ} \mathrm{C}\right)$, where compressive stresses $\sigma_{\mathrm{c}}$ at a higher compressive velocity $v_{\mathrm{c}}$ are higher by about $30 \%$. This indicates that at higher temperature $T$, the viscosity of the test material begins to prevail over the properties of elasticity. This results in the dependence of the macroscopic mechanical properties of the material on the deflection velocity, as a result of which the effect of the obtained compressive stresses $\sigma_{\mathrm{c}}$ on the value of the compressive velocity $v_{\mathrm{c}}$ becomes observable [63].

Approximating the start curve $\left(0<\varepsilon_{\mathrm{c}}<5 \%\right)$ of the material compression characteristics (Fig. 10) using a linear function, using the least squares method, it is possible to determine the proportionality modulus at compression $E_{\mathrm{c}}$, with the correlation coefficient $R^{2}>0.994$ (Fig. 14), from the dependency: 
Table 3 Characteristics of the belt plasticizing force $F_{\mathrm{pl}}$ with a diameter $d=12 \mathrm{~mm}$ with the plasticizing velocities $v_{\mathrm{pl}}$ which are equal to 2 , $4,8,12$ and $16 \mathrm{~mm} / \mathrm{min}$, depending on the plasticizing time $t$ and the displacement of the belt end $s$ relative to the hot plate: II-phase of a clear and repeated increase in the plasticizing force $F_{\text {pl }}$, III-phase of the variable force curve $F_{\mathrm{pl}}$ depending on the plasticizing velocity $v_{\mathrm{pl}}$
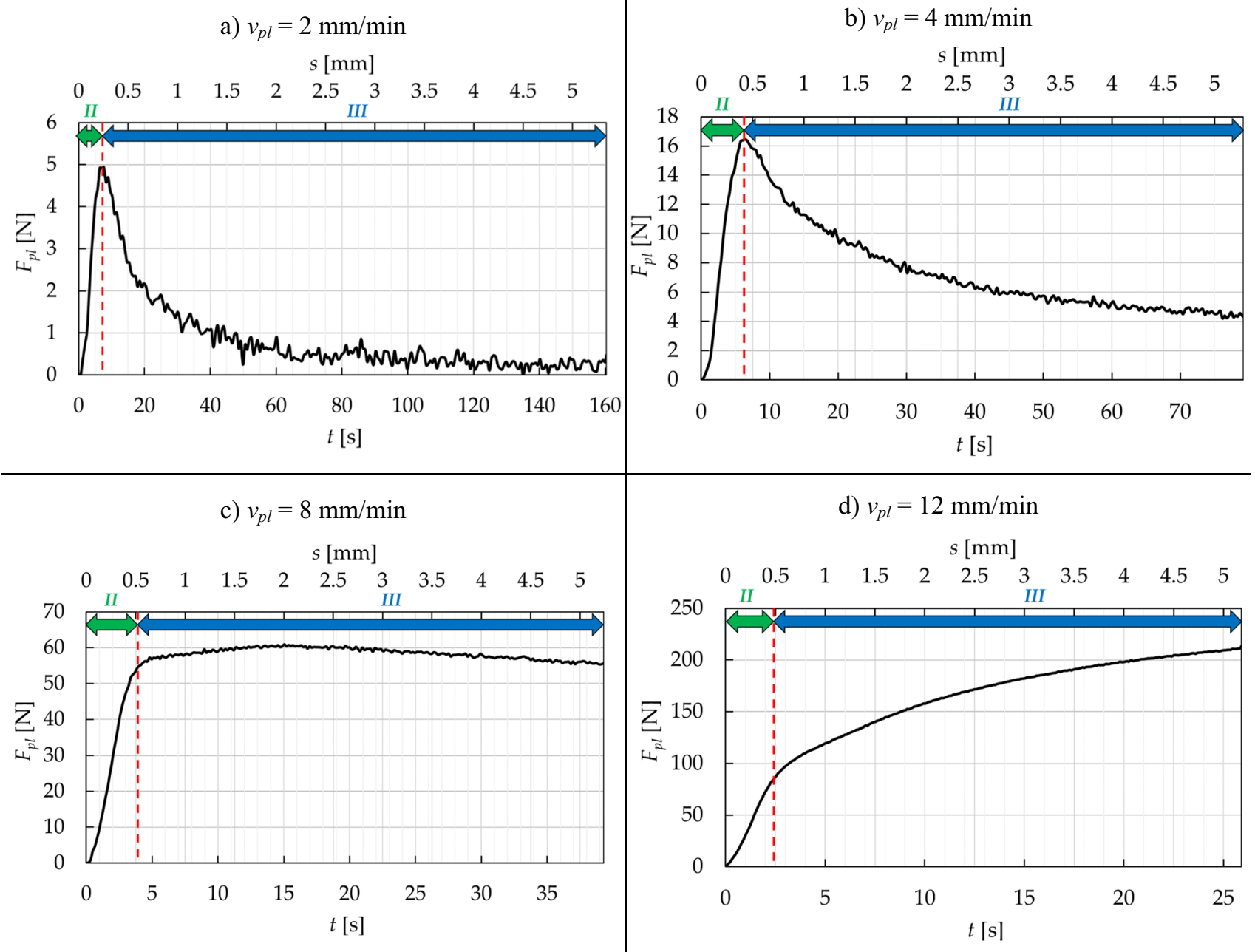

e) $v_{p l}=16 \mathrm{~mm} / \mathrm{min}$

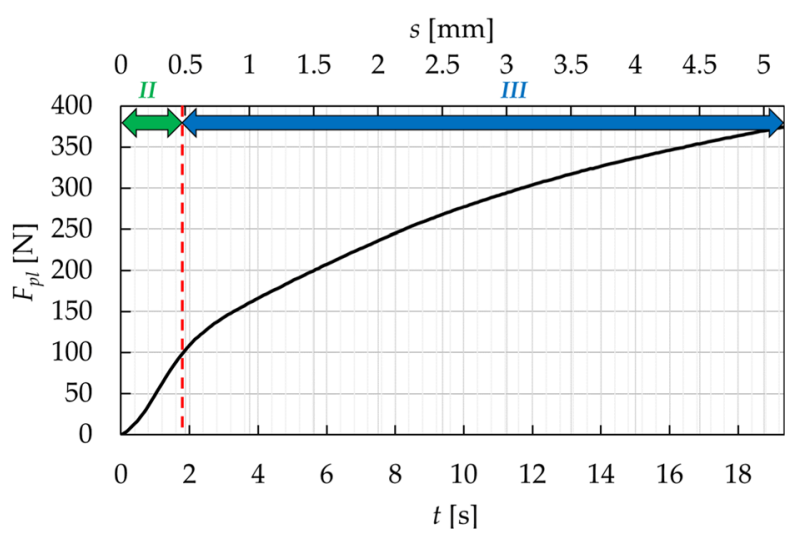


Table 4 Characteristics of the belt plasticizing force $F_{\mathrm{pl}}$ with a diameter $d=18 \mathrm{~mm}$ with the plasticizing velocities $v_{\mathrm{pl}}$ which are equals to $2,4,8,12$ and $16 \mathrm{~mm} / \mathrm{min}$, depending on the plasticizing time $t$ and the displacement of the belt end $s$ relative to the hot plate: II- phase of a clear and repeated increase in the plasticizing force $F_{\mathrm{pl}}$, III-phase of the variable force curve $F_{\mathrm{pl}}$ depending on the plasticizing velocity $v_{\mathrm{pl}}$

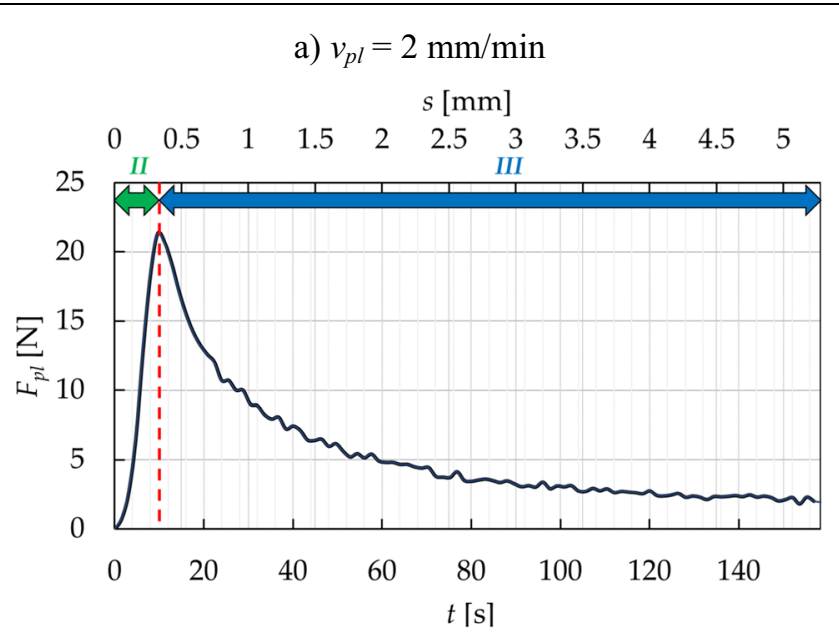

c) $v_{p l}=8 \mathrm{~mm} / \mathrm{min}$

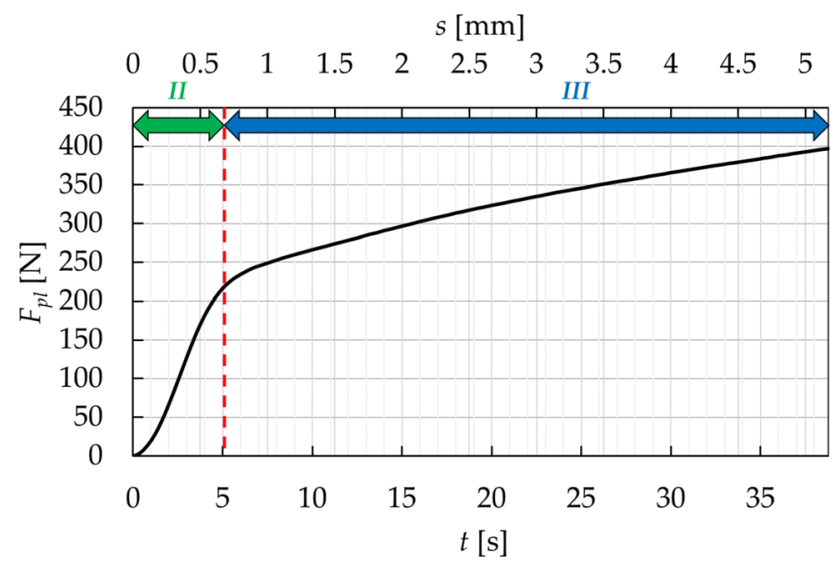

a) $v_{p l}=4 \mathrm{~mm} / \mathrm{min}$
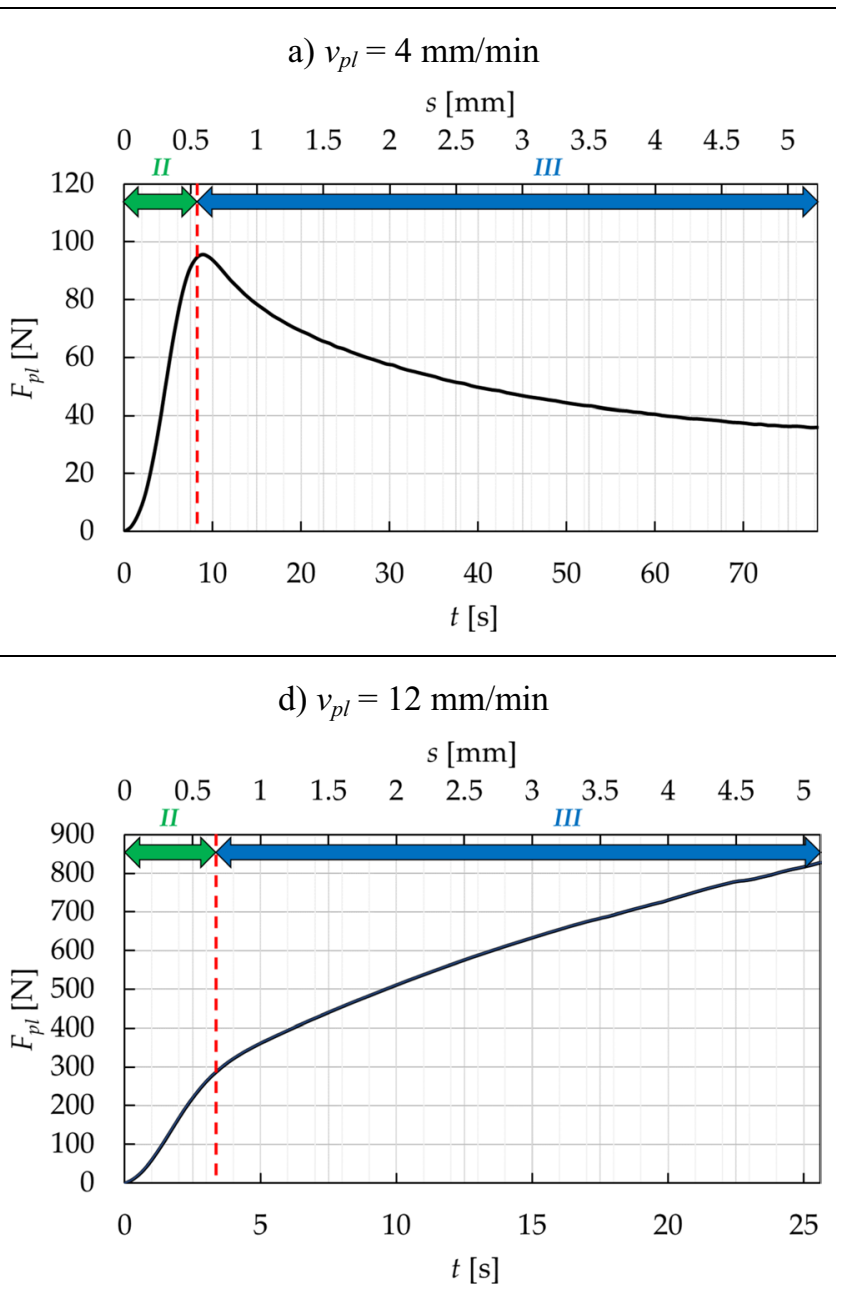

e) $v_{p l}=16 \mathrm{~mm} / \mathrm{min}$

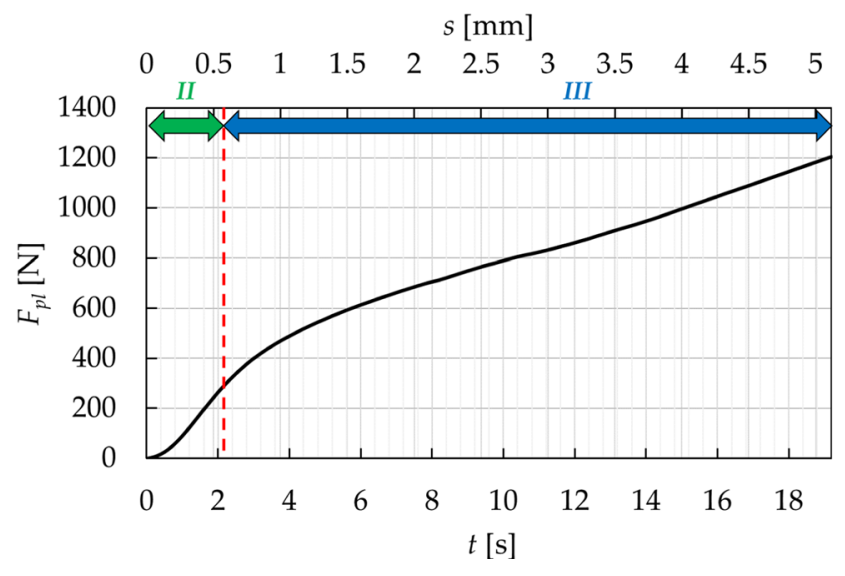




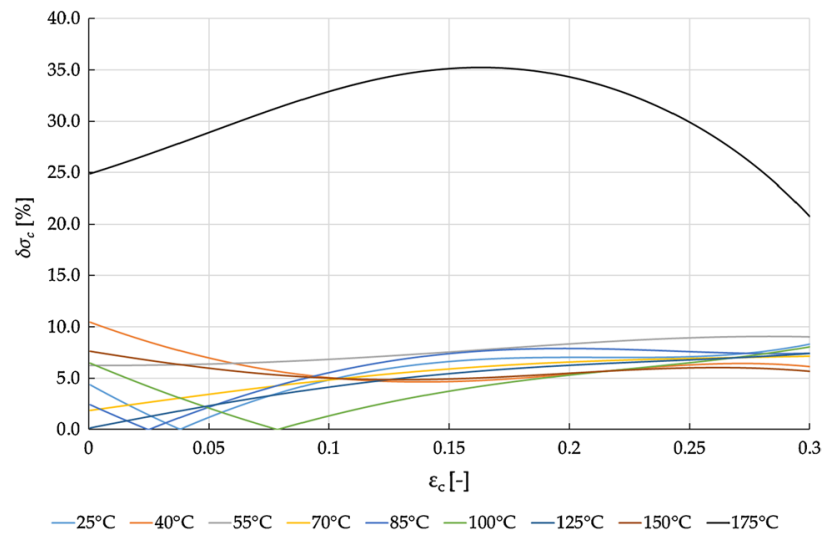

Fig. 13 The correlation of the average percentage difference $\delta \sigma_{\mathrm{c}}$ between the compressive stresses $\sigma_{\mathrm{c}}$ for the two compressive velocities $v_{\mathrm{c} 1}=1 \mathrm{~mm} / \mathrm{min}$ and $v_{\mathrm{c} 10}=10 \mathrm{~mm} / \mathrm{min}$ to the strain $\varepsilon_{\mathrm{c}}$, at different temperature values $T$ of the compressed specimen

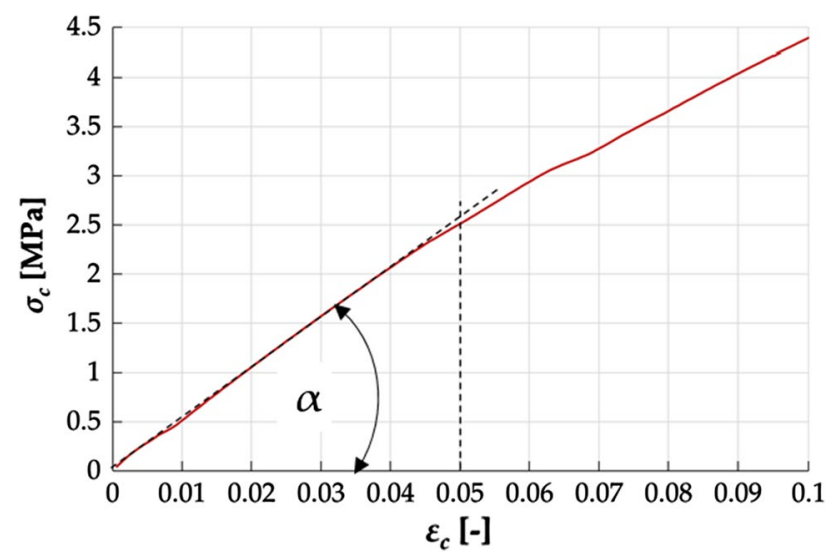

Fig. 14 Methodology for determining the proportionality modulus $E_{\mathrm{c}}$ at compression

$E_{\mathrm{c}}=\tan \alpha=\frac{\sum\left[\left(\varepsilon_{\mathrm{c}}-\overline{\varepsilon_{\mathrm{c}}}\right) \times\left(\sigma_{\mathrm{c}}-\overline{\sigma_{\mathrm{c}}}\right)\right]}{\sum\left(\varepsilon_{\mathrm{c}}-\overline{\varepsilon_{\mathrm{c}}}\right)^{2}}$.

Based on the obtained results, the correlation between the modulus of elasticity $E_{\mathrm{c}}$ and the temperature $T$ at compression was determined (Fig. 15), for two compression velocities $v_{\mathrm{c}}$.

Analyzing the presented characteristics, it can be concluded that the determined value of the modulus $E_{\mathrm{c}}$ decreases with an increase in temperature $T$, regardless of the compression velocity $v_{\mathrm{c}}$, which is the expected effect. The relative difference between the values of the modulus of elasticity at $\delta E_{\mathrm{c}}$ for both compression velocities can be determined from the dependency:

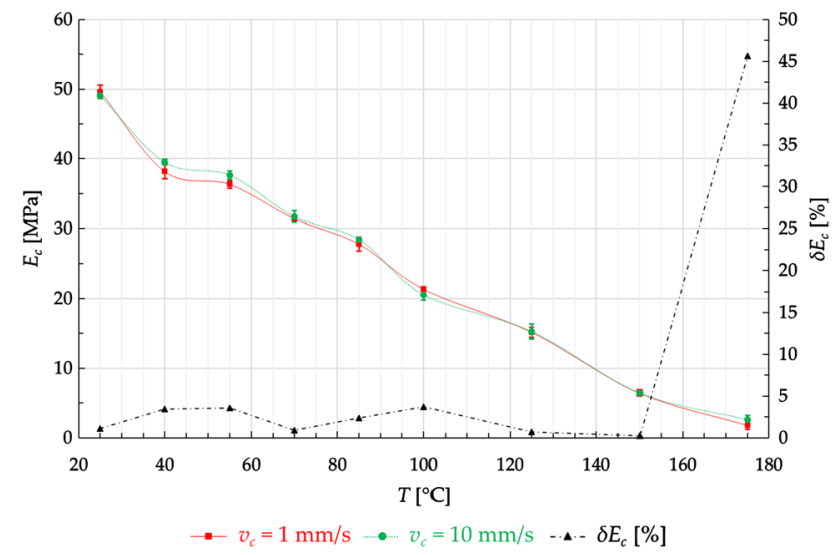

Fig. 15 The correlation between the longitudinal modulus of elasticity $E_{\mathrm{c}}$ and the difference between the determined moduli $\delta E_{\mathrm{c}}$ and the specimen temperature $T$ for two compression velocities $v_{\mathrm{c} 1}=1 \mathrm{~mm} /$ min and $v_{\mathrm{c} 10}=10 \mathrm{~mm} / \mathrm{min}$

$\delta E_{\mathrm{c}}(T)=\frac{\left|E_{\mathrm{c} 10}-E_{\mathrm{c} 1}\right|}{E_{\mathrm{c} 10}} \times 100 \%$,

where $E_{\mathrm{c} 1}$ is the modulus at velocity $v_{\mathrm{c} 1}=1 \mathrm{~mm} / \mathrm{min}, E_{\mathrm{c} 10}$ is the modulus at velocity $v_{\mathrm{c} 10}=10 \mathrm{~mm} / \mathrm{min}$. As in the case of compressive stress values $\sigma_{\mathrm{c}}$ (Fig. 15), for temperature $T<175{ }^{\circ} \mathrm{C}$, the differences between the determined values of the proportionality modulus at compression $\delta E_{\mathrm{c}}$ are small and do not exceed $5 \%$ in this case. An increase in specimen temperature $T$ results in an increased role of the viscous properties of the material, which is demonstrated by an increase in the difference in the value of the proportionality modulus $\delta E_{\mathrm{c}}$ to about $45 \%$, with a change in the deformation velocity $v_{\mathrm{c}}$.

The dependency of the proportionality modulus $E_{\mathrm{c}}$ averaged over two compression velocities to specimen temperature $T$ can be approximated using the least squares method with a correlation coefficient $R^{2}>0.979$ to the following dependency:

$E_{\mathrm{c}}(T)=a_{1} \times e^{-\left(\frac{T-a_{2}}{a_{3}}\right)^{2}}$,

where $a_{1} \ldots a_{3}$ are constant factors. This results in the correlation between the averaged proportionality modulus at compression $E_{\mathrm{c} \_ \text {avg_EMP }}$ and temperature $T$ (Fig. 16).

The compression tests of the belt material were carried out at a maximum temperature $T=175{ }^{\circ} \mathrm{C}$. Above this limit, the belt specimens are self-destructed as a result of clear material flow, without compressive force. Taking into account the fact that the process of hot plate welding takes place at higher temperatures, it is necessary to know the proportionality modulus at compression $E_{\mathrm{c}}$ in a wider temperature range $T$. Due to the fact that with the assumed test methodology it is impossible to determine the modulus of proportionality $E_{\mathrm{c}}$ and compressive 


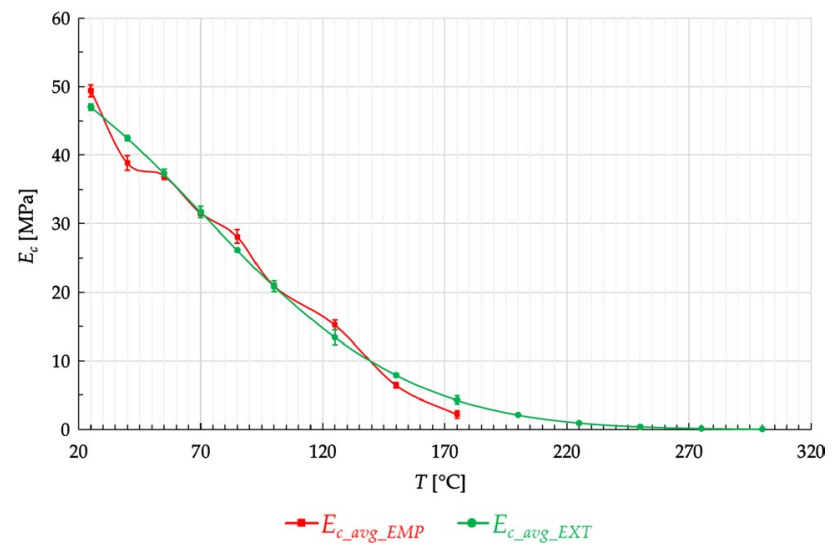

Fig. 16 The correlation between the averaged modulus of proportionality $E_{\mathrm{c}}$ and the difference between the determined moduli $\delta E_{\mathrm{c}}$ and the specimen temperature $T$ for two compression velocities $v_{\mathrm{c}}=1 \mathrm{~mm} / \mathrm{min}$ and $v_{\mathrm{c}}=10 \mathrm{~mm} / \mathrm{min}$

stresses $\sigma_{\mathrm{c}}$ empirically at temperature $T$ exceeding $175^{\circ} \mathrm{C}$, the obtained variability function of the modulus $E_{\mathrm{c}}$ relative to specimen temperature has been extrapolated for a temperature range $T$ extended to $300{ }^{\circ} \mathrm{C}$. By performing this operation for the averaged proportionality modulus at compression $E_{\text {c_avg_EMP }}$, the expected value of the proportionality modulus at compression $E_{\text {c_avg_EXT }}$ is obtained in the temperature range $T$ from 25 to $300{ }^{\circ} \mathrm{C}$ (Fig. 16).

As can be inferred from the analysis of the mechanical properties during compression of the belt material at variable temperature $T$, the values of the basic mechanical properties do not depend on the compression velocity $v_{\mathrm{c}}$ at temperature $T$ not exceeding approximately $175^{\circ} \mathrm{C}$. This observation allows us to conclude that for this viscoelastic material, in this temperature range, the dominant effect of loading it is deformation, mainly of elastic nature. The viscous behavior of the material is revealed at a higher temperature.

The performed dynamic thermomechanical analysis study consisted in essence of oscillatory twisting of the specimen, at a constant maximum oscillation amplitude $A$ and a constant frequency $f$. The obtained results (Fig. 11), however, are not satisfactory from the point of view of the analysis of the operation of plasticizing the belt material on the hot plate. This is due to the fact that the characteristics of the constituents of the transverse modulus of elasticity $G$ and the loss factor $\operatorname{tg} \delta$, do not directly provide useful information in the context of compressing the material at elevated temperature. It is necessary to carry out an analysis of the material viscosity $\eta$, whose value will play an important function in further studies.

Analyzing the test conditions of the dynamic thermomechanical analysis, the maximum amplitude of the dimensionless transverse deformation $\gamma_{0}$ can be assumed as [63, 64, 68]:

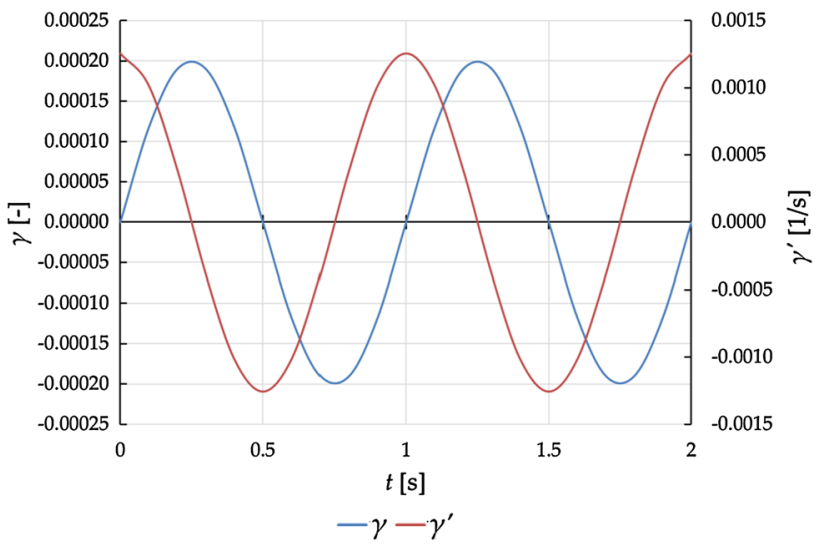

Fig. 17 Characteristics of deformation variability $\gamma$ and deformation velocity $\gamma$ ' depending on the duration of the DMTA test

$\gamma_{0}=A$.

Therefore, the change in deformation $\gamma(t)$ over time is described by the dependency:

$\gamma(t)=\gamma_{0} \times \sin (\omega \times t)$,

and change in the deformation velocity $\gamma^{\prime}(t)$ :

$\gamma^{\prime}(t)=\gamma_{0} \times \omega \times \cos (\omega \times t)$,

where $t$ is the test time, $\omega$ is the circular oscillation frequency, described by the dependency:

$\omega=2 \times \pi \times f$.

Taking into account the specified oscillation parameters, it is possible to determine the course of deformation $\gamma$ and the deformation velocity $\gamma^{\prime}$ as a function of time $t$. On this basis, it is possible to determine the maximum deformation velocity $\gamma^{\prime}(t)$, obtained during the DMTA test, whose maximum absolute value is approximately $1.25 \times 10^{-3} \mathrm{~s}^{-1}$ (Fig. 17).

This value is crucial for the analysis of material behavior. The analysis of these velocities is used in modeling the process of molten polymer processing [63]. Taking into account the standard, typical characteristic curves of polymer flow, it can be concluded that the considered range of deformation velocity lies in the first region of the Newtonian flow of polymer material, for which the value of this velocity does not usually exceed $10^{1} \mathrm{~s}^{-1}[63,64,69]$. This means that in this range of deformation velocity $\gamma^{\prime}$, it is possible to take into account the laws concerning the Newtonian fluid, that is the behavior of a viscous polymer material such that any stresses $\tau(\sigma)$ depend linearly on the deformation velocity $\gamma^{\prime}$. This determines the conclusion that the total modulus of elasticity $G$ (or $E$ ) during cyclic deformations does not depend on the amplitude of deformations $\gamma_{0}$ for the viscoelastic body, 
which this polymer undoubtedly is [64]. Therefore, the studied material can be treated as a viscoelastic body complying with the Newtonian flow law, within the studied range of deformation velocity $\gamma^{\prime}$.

Therefore, further analysis of the obtained results is warranted (Fig. 11) in the context of determining the dynamic viscosity of the material $\eta$, based on the components of the transverse modulus of elasticity $G$ [65].

On this basis, it is possible to determine the total averaged, experimentally determined dynamic viscosity $\eta_{\text {EXP_AVG }}$ and its variability together with temperature $T$ (Fig. 18), using the dependency [63, 65]:

$\eta_{\text {EXP_AVG }}(T)=\frac{|G|}{\omega}=\frac{\sqrt[2]{\left(G^{\prime}\right)^{2}+\left(G^{\prime \prime}\right)^{2}}}{\omega}$.

Since the maximum temperature $T$ during the DMTA test was limited to $180^{\circ} \mathrm{C}$, and the welding process takes place at a temperature of up to $300{ }^{\circ} \mathrm{C}$ [4], there is a need to extend the range of temperature $T$ for which the dynamic viscosity $\eta$ will be determined. In this case, for materials with a welldefined microstructure (crystalline, amorphous or semi-crystalline body), extrapolation is typically used for the range of variation of any mechanical parameter (e.g., viscosity $\eta$ ) together with temperature $T$, using known empirical laws $[37,42,63,70]$. For partially crystalline plastics, this is the Williams-Landel-Ferry law (WLF) in the following form:

$\eta(T)=\eta_{0} \times e^{\left[\frac{-C_{1} \times\left(T-T_{0}\right)}{C_{2}+\left(T-T_{0}\right)}\right]}$,

where $\eta_{0}$ is the viscosity at reference temperature $T_{0}, C_{1}$ and $C_{2}$ is the are the material constants. In the case of amorphous plastics, Arrhenius law is usually used in the following form:

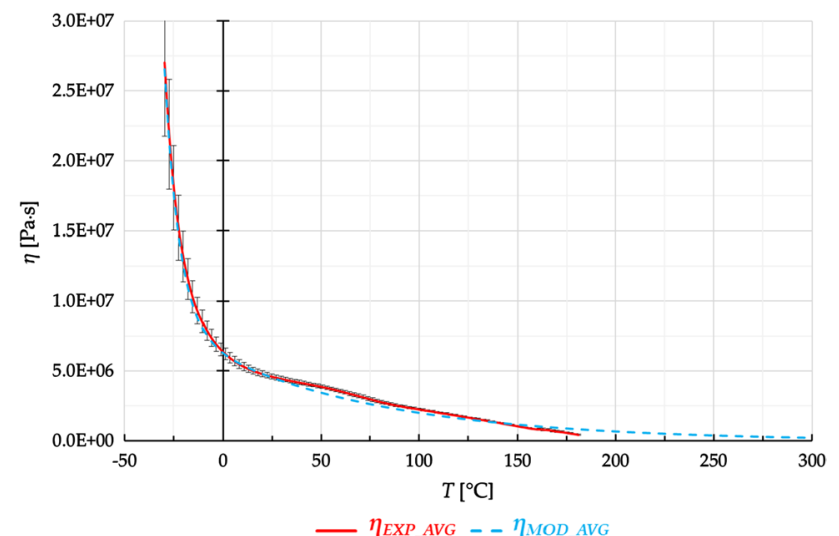

Fig. 18 Dynamic viscosity variation characteristics $\eta$ : $\eta_{E X P_{A V G}}$ averaged, experimentally determined, $\eta_{M O D \_A V G}$ model, based on extrapolating the curve
$\eta(T)=\eta_{0} \times e^{\left[\frac{E}{R} \times\left(\frac{1}{T}-\frac{1}{T_{0}}\right)\right]}$,

where $R$ is the gas constant, $E$ is the activation energy of the material. Unfortunately, in this case, both the solid material equations WLF (13) and the activation energy of the material (14) are unknown parameters, as is the actual structure of the material. Therefore, in order to extend the range of known dynamic viscosity $\eta$, the empirical data were approximated using the least squares method with a correlation coefficient $R^{2}>0.9975$. Next, the curve was extrapolated to determine the model viscosity $\eta_{\text {MOD_AVG }}$ in the extended temperature range $T$ (Fig. 18). Therefore, the dependency of this parameter to temperature $T$, takes the following form:

$\eta_{\mathrm{S} \_\mathrm{MOD}}(T)=a_{1} \times e^{\left(b_{1} \times T\right)}+a_{2} \times e^{\left(b_{2} \times T\right)}$,

where $a_{1}, a_{5}, b_{1}, b_{2}$ are constant factors, determined empirically.

It is important, however, that the physical phenomena occurring in plasticizing the material in the process of hot plate welding are completely different from those occurring in the DMTA test. The main difference is the method of deformation of the material, which during welding involves compression, rather than torsion. Therefore, the results of testing the dynamic viscosity $\eta$ of the material in the transverse direction are not sufficient. It is necessary to determine the viscosity in the longitudinal direction. For this purpose, the obtained deformation velocities should be analyzed (Fig. 19).

Analyzing the deformation of the belt material during plasticizing, it should be noted that the deformation is not uniform over the entire length of the compressed belt, which distinguishes this situation from the model compression process. In this case, the deformation of the material occurs on the section $h_{1}$ located between the belt grip and the hot plate. Taking into account the fact that the belt material deforms unilaterally, as a result of a decrease in strength under the influence of elevated temperature (heating occurs unilaterally), it can be assumed that the part of the belt with temperature $T=T_{0}$ is perfectly rigid, in comparison with the part whose temperature exceeds $T_{0}$ (comparing in particular to the section of the material heated to temperature $T_{\mathrm{w}}$ ). Therefore, it can be assumed that during plasticizing only the section of the belt of length $h$ is subject to deformation. Thus, the deformation to which the belt is subjected will take the value:

$\mathrm{d} \varepsilon=\frac{\mathrm{d} h}{h}$.

The following dependency is also true: 


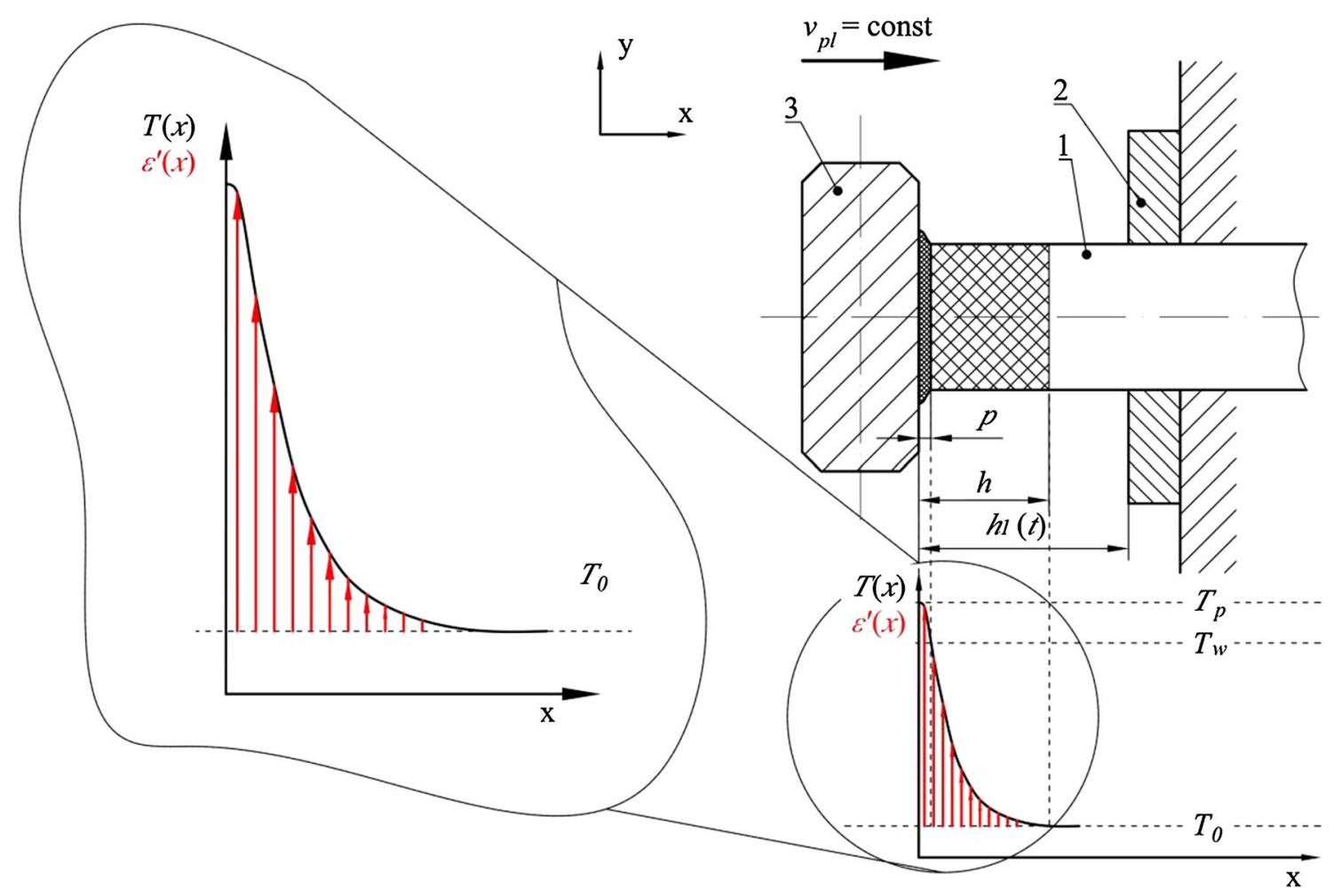

Fig. 19 Belt plasticizing during hot plate welding-expected temperature distribution in the belt axis and deformation velocity: 1-fixed belt end, 2-grip, 3-hot plate; $v_{\mathrm{pl}}$ plasticizing velocity, $T_{p}$ temperature of the hot plate, $T_{w}$ welding temperature, $T_{0}$ environment temper-

$\mathrm{d} h=v_{\mathrm{pl}} \times \mathrm{d} t$,

therefore, the deformation velocity can be described by the following dependency:

$\frac{\mathrm{d} \varepsilon}{\mathrm{d} t}=\varepsilon^{\prime}=\frac{\mathrm{d} h}{h} \times \frac{1}{\mathrm{~d} t}=\frac{v_{\mathrm{pl}}}{h}$.

However, it should be noted that the delivery of heat to the belt material by means of the hot plate (Fig. 2) causing the temperature of the material to rise, will result in different susceptibility to deformation. As a result, the distribution of the deformation velocity $\varepsilon$ ' along the belt axis will not be homogeneous, and the expected effect is its relation to the temperature distribution $T(x)$ (Fig. 19). In addition, the value of the distance $h$ also depends on the temperature distribution $T(x)$. Without knowledge of this function, it is impossible to determine precisely the distribution of the deformation velocity $\varepsilon^{\prime}$. However, taking into account the performed tests of plasticizing the material, they occur at a certain maximum speed:

$v_{\text {pl_MAX }}=16 \frac{\mathrm{mm}}{\min }=0.27 \frac{\mathrm{mm}}{\mathrm{s}}$, ature, $p$ - belt plasticizing distance, $h$ section heated to a temperature higher than the environment temperature environment, $h_{1}$ distance of belt extension from the grip, $\varepsilon^{\prime}$ deformation velocity during plasticizing

and the minimum distance $h$ at which the material can be plasticized in the area between the grip and the hot plate [45]:

$h_{M I N}=0.2 \mathrm{~mm}$,

the maximum deformation velocity will be:

$\varepsilon^{\prime}=1.35 \frac{1}{\mathrm{~s}}$.

Regardless of the actual distribution of the plasticizing velocity $\varepsilon^{\prime}$, its value cannot be greater. Therefore, during belt plasticizing under consideration, deformation velocities remain in the Newtonian viscosity range, i.e., below $10^{1} \mathrm{~s}^{-1}$. The viscosity value, which needs to be known in order to model the process, is, therefore, possible to be determined on the basis of the performed viscosity tests in DMTA analysis with assumed parameters.

In order to determine the longitudinal viscosity $\eta_{\mathrm{e}}$ for compressive/tensile applications, Trouton's definition of viscosity can be used, according to which $[46,71]$ : 
$\eta_{\mathrm{e}}=3 \times \eta$

On this basis, using the dependencies (15) and (22) (Fig. 18) it will be possible to adopt the appropriate viscosity value to model belt plasticizing.

Some of the most interesting results were achieved during the attempts at plasticizing the belt material on the hot plate (Tables 3 and 4). In II phase of this operation, regardless of the plasticizing velocity $v_{\mathrm{pl}}$ and the band diameter $d$, a proportional, approximately straight-line and repeated increase in the material plasticizing force $F_{\mathrm{pl}}$ can be distinguished with the specimen displacement $s$ relative to the hot plate.

In the further course of belt plasticizing, it is also possible to distinguish the third phase (III), in which the value of the plasticizing force $F_{\mathrm{pl}}$ changes in most cases in a nonlinear way (Tables 3 and 4). The characteristic of its course, depending on the plasticizing time $t$ or the specimen displacement $s$, depends on the plasticizing velocity $v_{\mathrm{pl}}$ and the belt diameter $d$.

Analyzing the course of phase III of plasticizing a belt with a diameter $d=12 \mathrm{~mm}$ (Table 3 ), it can be observed that for velocities $v_{\mathrm{pl}}$ equal to $2 \mathrm{~mm} / \mathrm{min}$ and $4 \mathrm{~mm} / \mathrm{min}$, the value of the force $F_{\mathrm{pl}}$ decreases non-linearly with an increase in plasticizing time $t$. In the case of velocities $v_{\mathrm{pl}}$ equal to $12 \mathrm{~mm} / \mathrm{min}$ and $16 \mathrm{~mm} / \mathrm{min}$, the value of the force $F_{\mathrm{pl}}$ increases non-linearly with an increase in plasticizing time $t$. An interesting observation is also the course of the plasticizing force $F_{\mathrm{pl}}$ at velocity $v_{\mathrm{pl}}$ of $8 \mathrm{~mm} / \mathrm{min}$, when the force $F_{\mathrm{pl}}$ assumes values that are almost constant, independent of plasticizing time $t$.

Similar dependencies can be observed when the belt with a diameter $d=18 \mathrm{~mm}$ is plasticized (Table 4 ), the difference being that for plasticizing velocity $v_{\mathrm{pl}}=8 \mathrm{~mm} / \mathrm{min}$, the value of the force $F_{\mathrm{pl}}$ increases non-linearly, in contrast to the belt with a smaller diameter $d$. At other values of plasticizing velocity $v_{\mathrm{pl}}$, similar phenomena were observed as in the case of the belt with a diameter $d=12 \mathrm{~mm}$.

Analyzing the course of phases II and III, it is possible to approximate the obtained characteristics, using the least squares method, with a correlation coefficient $R^{2}>0.996$, resulting in a diagram of the correlation of the force plasticizing the belt material and time $t$ or displacement $s$, based on a mathematical description (Fig. 20).

The interpretation of the phenomenon of proportional increase in the value of the plasticizing force $F_{\mathrm{pl}}$ in the phase II of the plasticizing operation can be the fact that the process of heating the belt material is not instantaneous. In contrast to the often accepted assumptions about the heating of the material by the hot plate, which consist in modeling this operation as a one-sided heating of a semi-infinite body with the application of a heat source to its only symmetry surface [9, 13, 18, 19], the heat exchange between the specimen and the hot plate under real conditions is accompanied

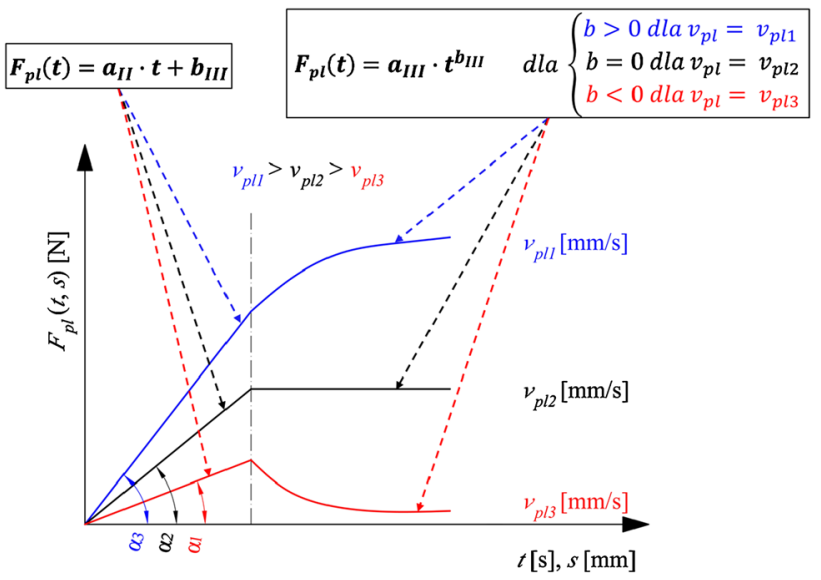

Fig. 20 Characteristics of change in belt plasticizing force $F_{\mathrm{pl}}$ as a function of operation time $t$ or belt displacement relative to the hot plate $s: F_{p l}$ force needed to plasticize the material, $t$ plasticizing time, $s$ belt displacement relative to the hot plate, $v_{p l}$ plasticizing velocity, $a_{\mathrm{II}}$ and $b_{\mathrm{II}}$-constant factors of linear range, $a_{\mathrm{III}}$ and $b_{\mathrm{III}}$-constant factors of the function describing phase III of plasticizing

by a certain thermal resistance $[39,42,45]$. In addition, each material is characterized by a certain thermal inertia resulting from a finite value of the thermal diffusion coefficient $a$ [72].

Therefore, assuming that the plasticizing velocity $v_{\mathrm{pl}}$ is constant and non-zero, at this phase, there is a phenomenon of partial compression of the still unplasticized solid, so that an increase in the pressing force $F_{\mathrm{pl}}$ with the displacement $s$ is the expected effect. According to the results of the compression tests (Fig. 10), the application of the compressive force $F_{\mathrm{pl}}$ to the material in the range of small deformations is characterized by a linear range, which is reflected in phase II of plasticizing the material (Tables 3 and 4). It is obvious, however, that the directional coefficient of this straight $a_{\mathrm{II}}$ (Fig. 20) changes its value with the change of velocity $v_{\mathrm{pl}}$ and diameter $d$, whereas the correlation between these values is positive.

In the case of phase III of this operation, the observed change in the characteristics of the course of the plasticizing curve (Tables 3, 4 and Fig. 20) depending on the constant and non-zero velocity $v_{\mathrm{pl}}$ and diameter $d$, is mainly due to the limited material heating velocity. This is related to a finite and approximately constant value of the thermal diffusion coefficient $a$, approximately independent of plasticizing velocity $v_{\mathrm{pl}}$.

Therefore, in phase III there are 3 types of phenomena, the effects of which can be observed on the basis of the analysis of the course of the plasticizing force $F_{\mathrm{pl}}$ (Fig. 20) and the shape of the specimens after plasticizing (Fig. 21):

- in the case of a low value of the plasticizing velocity $v_{\text {pl1 }}$ (for the belt with the diameter $d=12 \mathrm{~mm}$ it is $2 \mathrm{~mm} / \mathrm{min}$ 


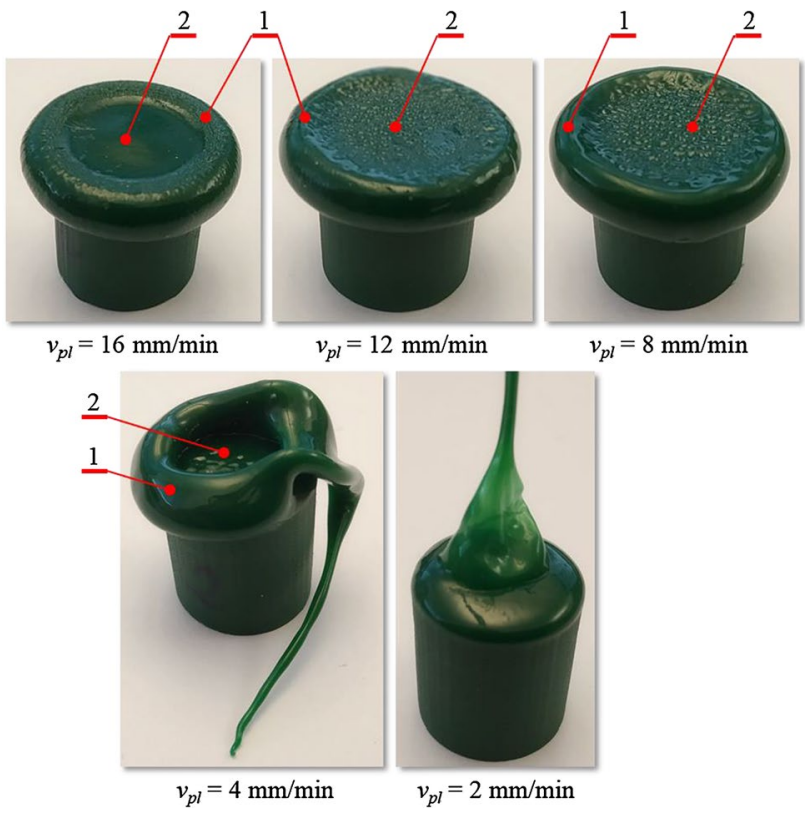

Fig. 21 Specimens after plasticizing tests on the hot belt plate with a diameter $d=12 \mathrm{~mm}: v_{p l}$ plasticizing velocity, 1-flash area, 2-core of the belt

and $4 \mathrm{~mm} / \mathrm{min}$ ), the material is overheated as a result of too low a value of the specimen displacement velocity $v_{\mathrm{pl}}$ relative to the heating velocity. This results in a clear decrease in the value of the plasticizing force $F_{\mathrm{pl}}$ (Fig. 20), as a result of compression of the material subject to plastic flow. Analyzing the shape of the specimen after the plasticizing operation (Fig. 21), no clear boundary can be observed between the core (2) and the flash (1). This is due to excessive deformation of the material, its melting and flashing from the working area. It can therefore be concluded that such plasticizing is excessive and causes unnecessary loss of energy and material. In industrial practice, however, this phenomenon can cause additional design and technological problems associated with the outflow of molten polymer from the working area of the machine,

- in the case of a high value of the plasticizing velocity $v_{\mathrm{pl}}$ (for the belt with the diameter $d=12 \mathrm{~mm}$ it is $12 \mathrm{~mm} /$ $\min$ and $16 \mathrm{~mm} / \mathrm{min}$ ), the material is under-heated, since the velocity of pressing the specimen to the plate $v_{\mathrm{pl}}$ is significantly greater than the velocity of heat dissipation in the polymer structure. As a result, it is insufficiently plasticized, which in principle means the material is being compressed in the solid state. As a result, the plasticizing force increases significantly in the further course of this operation (Fig. 20). The observable effect is the shiny structure of the core (2), from which the plasticized material is completely extruded into the flash area (1) (Fig. 21). This phenomenon is disadvantageous because the core of the material does not have sufficient temperature and degree of plasticity to form a permanent connection. In addition, the value of the technological forces of the process is adversely increased, which also worsens its energy efficiency,

- in the case of an intermediate value of the plasticizing velocity $v_{\mathrm{p} 12}$ (for a belt with a diameter $d=12 \mathrm{~mm}$, this is about $8 \mathrm{~mm} / \mathrm{min}$ ), the material is properly plasticized. By analyzing the correlation between the plasticizing force $F_{\mathrm{pl}}$ and time $t$ (Fig. 20), an almost constant course of its value can be observed, which indicates that there is a balance between heat conduction and deformation of the material. The observable effect of this phenomenon is uniform melting of both the flash area (1) and the core (2) (Fig. 21). Such a course of the plasticizing operation can be considered effective.

The next very interesting issue is the correlation between plasticizing velocity $v_{\mathrm{pl}}$ and plasticizing time $t_{\mathrm{pl}}$. Due to controlling the $v_{\mathrm{pl}}$ velocity in the automatic welding machine, and also during the plasticizing tests conducted on the MTS durometer, the plasticizing velocity fulfills the following condition:

$v_{\mathrm{pl}}=\frac{s}{t} \cong$ const $>0$.

Therefore, the negative correlation between displacement $s$ and time $t$ is obtained. Obviously, the velocity in the real application is not constant due to the speeding up and braking of the mechanism. As it can be noticed in the process cyclogram (Fig. 3), the shape of the velocity diagram is not rectangular, but trapezoidal. The same situation is present during the test in MTS Insight durometer. However, this phenomenon during process analysis can be omitted in both stages for the following reasons:

- during speeding up, because of the initial clearance between the end of the belt and the hot plate; increasing the velocity is realized during gap deleting,

- during braking, because of the fact that the required plasticizing distance is exceeded in this time; so, this phenomenon does not have any influence on necessary plasticizing distance.

On the basis of the obtained results (Tables 3 and 4), the analysis of the plasticizing time $t_{\mathrm{pl}}$ can be conducted. Consideration of the overall plasticizing time $t_{\mathrm{pl}}$ can be pointless, because of the fact that the value of this parameter depends on displacement $s$ which was set. Its value in the practical approach depends on the required plasticized distance $h$, whose value can depend on, e.g., sizing of the inequalities on the surface of the belt which should be melted. On the other hand, time $t_{\mathrm{pl}}$ depends also on plasticizing velocity $v_{\mathrm{pl}}$. It is 
obvious that increasing the plasticizing velocity $v_{\mathrm{pl}}$ gives the effect of decreasing the plasticizing time $t_{\mathrm{p}}$, considering the constant value of the required displacement $s$. The essence of the work conducted by the authors concerns formulation of the mathematical model of plasticizing, to find the most effective value of the plasticizing velocity $v_{\mathrm{pl}}$ which is necessary to obtain the required plasticization of the belt with possibly lowest energy consumption.

Additionally, performing an analysis of the time $t_{\mathrm{pl}}$ to obtain a hypothetical correlation between maximal plasticizing force $F_{\mathrm{pl} M A X}$ and plasticizing time $t_{\mathrm{pl}}$ may not give expected results, because of a different plasticizing course in the III phase, for different plasticizing velocity $v_{\mathrm{pp}}$. In the authors' opinion, better results can be obtained by designation of a new parameter-time to plasticizing phase change $t_{\mathrm{II}-\mathrm{III}}$. This parameter can give information about the moment of changing the plasticizing phase, from the second to the third. Analysis of this parameter can give an insight into the performance of the plasticizing operation. Its correlation with plasticizing velocity $v_{\mathrm{pl}}$ and sample diameter $d$ is given in the Fig. 22.

Analysis of the presented dependencies points out that phase change time $t_{\mathrm{II}-\mathrm{III}}$ decreases with increasing plasticizing velocity $v_{\mathrm{pl}}$, which is an expected effect. Both obtained characteristics can be approximated using the least squares method with a correlation coefficient $R^{2}>0.9996$ to the Fourier's model, which can be given by the equation:

$t_{\mathrm{pl}}=a_{0}+a_{1} \times \cos \left(a_{2} \times v_{\mathrm{pl}}\right)+b_{1} \times \sin \left(b_{2} \times v_{\mathrm{pl}}\right)$,

where $a_{0}, a_{1}, a_{2}, b_{1}$ and $b_{2}$ are constant factors, determined empirically. The variation of the phase change time $t_{\text {II-III }}$ becomes slighter with increasing plasticizing velocity $v_{\mathrm{pl}}$. This is due to the fact that the increase of the plasticizing velocity $v_{\mathrm{pl}}$, causes blurring of the differences between II

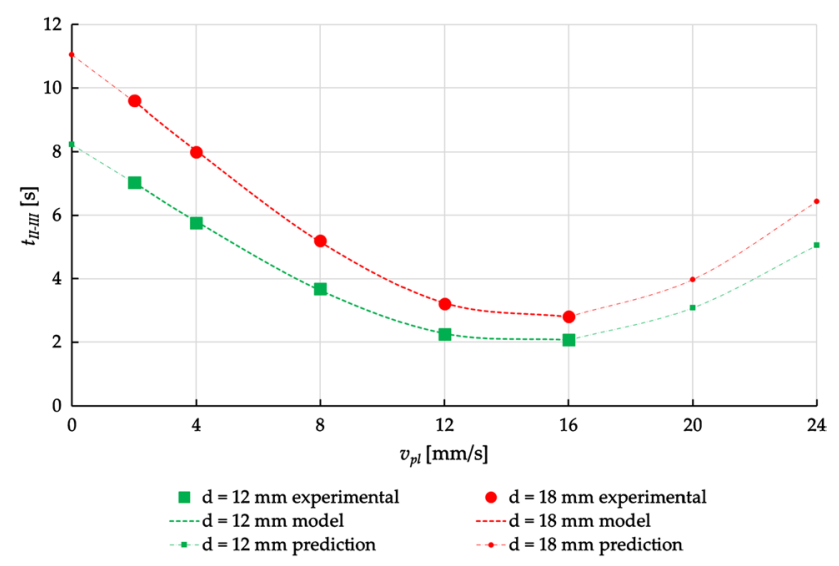

Fig. 22 Correlation between phase change time (II $\rightarrow$ III) and plasticizing velocity $v_{\mathrm{pl}}$ plasticizing velocity, $t_{\mathrm{II}-\mathrm{III}}$ time of plasticizing phase change and III phases. This fact can be observed in the gained plasticizing curves (Tables 3 and 4). The mathematical proof of this phenomenon can be obtained by the analysis of the derivative of the gained function (24), which tends to zero while the value of the independent variable $\left(v_{\mathrm{pl}}\right)$ goes to $16 \mathrm{~mm} / \mathrm{min}$.

The physical interpretation of this phenomenon may be the fact that increasing the plasticizing velocity gives an effect of insufficient heating, which causes compression of material at almost solid state, rather than pure plasticizing. In this case, particular plasticizing results (for different diameters $d$ ) become similar to each other and similar to the results from compression tests of a solid-state material. Due to this, for higher plasticizing velocity $v_{\mathrm{p}}$, the situation of less influence of sample diameter $d$ on plasticization effects becomes observable. Of course, obtained values of plasticizing force $F_{\mathrm{pl}}$ are different, but the shape of the plasticizing graph (rather a quasi-compression process) is similar.

Using the extrapolation method, the prediction of the analyzed function can be obtained (Fig. 22). According to the predicted models (such as before and after curve from tests), it can be observed that time $t_{\text {II-III }}$ grows up for smaller and also for higher plasticizing velocities $v_{\mathrm{pl}}$. For lower plasticizing velocity $v_{\mathrm{p}}$, this effect is expected, because with decreasing velocity $v_{\mathrm{p}}$, the dynamics of the process is lower so the heating operation lasts longer. For higher plasticizing velocity (in the predicted model for velocity higher than $16 \mathrm{~mm} /$ min in the Fig. 22), the effect of the increase of the time $t_{\text {II-III }}$ is unexpected. This fact may result from the changing nature of the process in this range of velocities, from plasticizing to pure compression. However, this fact should be checked in an experimental way in the future.

As can be seen in the studied plasticizing velocity $v_{\mathrm{pl}}$ range, the correlations between obtained time $t_{\text {II-III }}$ for both diameters $d$ are very similar. What is more, the difference between them is almost constant, which can be proved by obtaining the relative difference between the values of the phase change time at $\delta t_{\text {II-III }}$ for all of plasticizing velocities $v_{\mathrm{pl}}$ and two diameters $d$. Its value can be determined from the dependency:

$\delta t_{\mathrm{pl}}\left(v_{\mathrm{pl}}\right)=\frac{\left|t_{\mathrm{II}-\mathrm{III}(18)}-t_{\mathrm{II}-\mathrm{III}(12)}\right|}{t_{\mathrm{II}-\mathrm{III}(18)}} \times 100 \%$,

where $t_{\text {II-III(18) }}$ is the time of phase change for $18 \mathrm{~mm}$ of diameter and $t_{\mathrm{II}-\mathrm{III}(12)}$ is the time of phase change for $12 \mathrm{~mm}$ of diameter. Obtained differences can be presented on a correlation diagram (Fig. 23).

As can be seen, in the obtained dependency, the relative difference between time to phase change for both diameters is almost constant and reaches around $40 \%$. For belts with $d=18 \mathrm{~mm}$ the time $t_{\mathrm{IIIII}}$ is bigger. The 
physical interpretation of this phenomenon concerns the bigger volume of heated material (of about $56 \%$ ), which results from higher diameter $d$. Consequently, this sample demands more energy to increase the temperature. Assuming the constant power of the hot plate, which results in constant heat flux, according to thermodynamics' principles the heating time should be higher. This phenomenon is responsible for increasing the phase change time $t_{\text {IIIIII }}$ with increasing plasticizing velocity $v_{\mathrm{pl}}[72]$.

On the other hand, it should be noticed that the outer surface area is mainly responsible for energy losses, which is connected with convection and radiation $[18,35,45$, 72]. Increasing the sample diameter $d$, results in decreasing the ratio between outer surface area and volume, which can be described by the flowing formula:

$\Omega=\frac{A}{V}=\frac{\pi \times d \times h}{\frac{\pi \times d^{2}}{4} \times h}=\frac{4}{d}$,

where $d$ is the diameter of the belt, $A$ is the outer surface area, $V$ is the volume, $h$ is the the unitary height of the sample. As a result, the influence of surface area $A$ is smaller for belts with higher diameter $d$, so the relative energy losses for bigger diameters $d$ can be smaller. This phenomenon may cause a slight decrease of the time $t_{\mathrm{II}-\mathrm{III}}$ for bigger diameters $d$. However, this phenomenon is not balanced with the volume $V$ increase, so the effect of the time $t_{\text {IIIIII }}$ growth is observable.

Despite these facts, the most important issue is that the difference between phase change time $t_{\text {II-III }}$ is almost constant for these two diameters $d$. This observation proves that the heat exchange conditions for both types of samples were almost the same, so the results of the test could be compared.

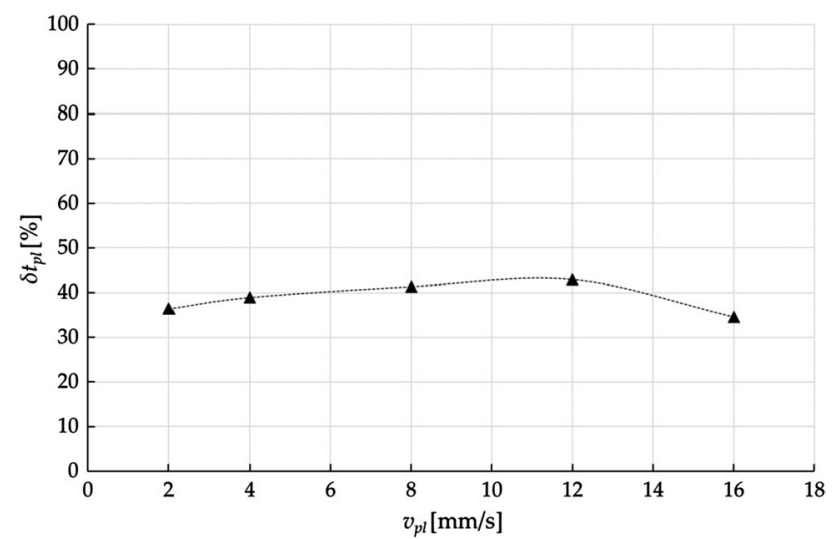

Fig. 23 Correlation between relative difference of phase change time $(I I \rightarrow I I I I I \rightarrow I I I) t_{\mathrm{II}-\mathrm{IIII}}$ and plasticizing velocity $v_{\mathrm{pl}}$ for both analyzed diameters $(d=18 \mathrm{~mm}$ and $d=12 \mathrm{~mm})$

\section{Conclusions}

The conducted research made it possible to identify the basic thermomechanical properties of drive belts undergoing the welding process. Their values will be used to formulate a mathematical model of the belt plasticizing operation, as the most important phase of the technological process of hot plate welding. The determined characteristics:

- compressive stresses $\sigma_{\mathrm{c}}$ and proportionality modulus at compression $E_{\mathrm{c}}$ from deformation velocity $\varepsilon_{\mathrm{c}}$ and temperature $T$,

- dynamic longitudinal viscosity $\eta_{e}$ from the temperature value at the specified deformation velocity,

- plasticizing force $F_{\mathrm{pl}}$ as a function of time $t$ or displacement $s$ at a constant plasticizing velocity $v_{\mathrm{p}}$,

will allow to formulate a mechanical model of the material during the plasticizing process, using the appropriate combination of basic models: Newton's, and Hooke's, especially the Kelvin-Voigt type with controlled parameters.

To carry out these activities in an appropriate manner, the following activities are planned in further research work:

- detailed testing of the belt material plasticizing will be performed, and the refinement will consist in narrowing the velocity range $v_{\mathrm{pl}}$ to values that allow obtaining a defined course of plasticizing in phase III of the operation (Fig. 20), for both $12 \mathrm{~mm}$ and $18 \mathrm{~mm}$ diameter belts. In addition, the results will be expanded with additional values of the hot plate temperature $T_{p}$,

- the temperature distribution $T(x)$ during belt heating will be determined using mathematical models of heat conduction in a rod with a moving heat source [72]. The adopted model will be verified empirically during detailed plasticizing studies,

- additional tests of the belt material compression will be performed, at compression velocities $v_{\mathrm{c}}$ as close as possible to the belt material plasticizing velocities $v_{\mathrm{pl}}$,

The obtained results will make it possible to determine a mathematical model of the plasticizing operation, based on a mechanical model, in which the technological parameters of this operation will be taken into account.

Author contributions Conceptualization: KW, KT, DW; Methodology: KW, KT, DW, Formal analysis and investigation: KW, JG, DW, Writing-original draft preparation: $\mathrm{KW}, \mathrm{KT}, \mathrm{DW}$; Writing-review and editing: JG, DW.

Funding This work was supported by Polish Minister of Education and Science by a research subsidy no. 0611/SBAD/0115. 


\section{Declarations}

Conflict of interest The authors have no relevant financial or non-financial interests to disclose.

Open Access This article is licensed under a Creative Commons Attribution 4.0 International License, which permits use, sharing, adaptation, distribution and reproduction in any medium or format, as long as you give appropriate credit to the original author(s) and the source, provide a link to the Creative Commons licence, and indicate if changes were made. The images or other third party material in this article are included in the article's Creative Commons licence, unless indicated otherwise in a credit line to the material. If material is not included in the article's Creative Commons licence and your intended use is not permitted by statutory regulation or exceeds the permitted use, you will need to obtain permission directly from the copyright holder. To view a copy of this licence, visit http://creativecommons.org/licenses/by/4.0/.

\section{References:}

1. Wałęsa K, Malujda I, Talaśka K, Wilczyński D. Process analysis of the hot plate welding of drive belts. Acta Mech et Auto. 2020;14(2):84-90. https://doi.org/10.2478/ama-2020-0012.

2. Wojtkowiak D, Talaśka K. Evaluation of the belt punching process efficiency based on the resistance force of the compressed material. Int J Adv Manuf Technol. 2020;110:717-27. https://doi.org/ 10.1007/s00170-020-05819-4.

3. Behabelt. Product Catalogue 2019/2020. Glottertal: Behabelt; 2019.

4. Wałęsa K, Malujda I, Talaśka K. Butt welding of round drive belts. Acta Mech Autom. 2018;12(2):115-26. https://doi.org/10. 2478/ama-2018-0019.

5. Wałessa K, Malujda I, Wilczyński D. Shaping the Parameters of Cylindrical Belt Surface in the Joint Area. Acta Mech Autom. 2020;13(4):255-61. https://doi.org/10.2478/ama-2019-0035.

6. Grewell D, Benatar A. Welding of plastics: Fundamentals and new developments. Int Polym Process. 2007;22(1):43-60. https://doi. org/10.3139/217.0051.

7. Amanat N, James NL, McKenzie DR. Welding methods for joining thermoplastic polymers for the hermetic enclosure of medical devices. Med Eng Phys. 2010;32(7):690-9. https://doi.org/10. 1016/j.medengphy.2010.04.011

8. Oliveira MJ, Bernardo CA, Hemsley DA. Morphology and mechanical behaviour of Polypropylene hot plate welds. Polym Eng Sci. 2004;41(11):1913-22. https://doi.org/10.1002/pen.10888.

9. Lin TT, Staicovici S, Benatar A. Non-contact hot plate welding of polypropylene. Annu Tech Conf ANTEC Conf Proc. 1996;1:1260-3.

10. Stokes VK. A phenomenological study of the hot-tool welding of thermoplastics. Part 1: polycarbonate. Polymer. 1999;40(23):623563. https://doi.org/10.1016/S0032-3861(98)00584-9.

11. Watson MN, Murch MG. Recent developments in hot plate welding of thermoplastics. Polym Eng Sci. 1989;29(19):1382-6. https://doi.org/10.1002/pen.760291909.

12. Gehde M, Bevan L, Ehrenstein GW. Analysis of the deformation of polypropylene hot-tool butt welds. Polym Eng Sci. 1992;32(9):586-92. https://doi.org/10.1002/pen.760320904.

13. Stokes VK. Experiments on the hot-tool welding of three dissimilar thermoplastics. Polymer. 1998;39(12):2469-77. https:// doi.org/10.1016/S0032-3861(97)00569-7.

14. Stokes VK. Toward a weld-strength data base for hot-tool welding of thermoplastics. Annu Tech Conf ANTEC Conf Proc. $1995 ; 1: 1280-4$.
15. Stokes VK. The vibration and hot-tool welding of polyamides. Polym Eng Sci. 2001;41(8):1427-39. https://doi.org/10.1002/pen. 10842.

16. Stokes VK. The hot-tool and vibration welding of Acrylonitrile-Butadiene-Styrene. Polym Eng Sci. 1997;37(4):692-701. https://doi.org/10.1002/pen.11713.

17. Stokes VK. Hot-tool and vibration welding of Poly(vinyl chloride). J Vinyl Addit Technol. 2000;6(3):158-65. https://doi.org/ 10.1002/vnl.10245.

18. Potente H. Zur Theorie des Heizelement-Stumpfschweißens. Kunstoffe. 1977;2:98-102.

19. Potente H, Schneiders J, Bornemann M. Theoretical model for the one-dimensional temperature and stress calculation of simple hot plate welded geometries. Macrmol Mater Eng. 2002;287(11):843-53. https://doi.org/10.1002/mame.20029 0014.

20. Potente $\mathrm{H}, \mathrm{Brüßel} \mathrm{A}$. Investigations into increasing weld strength through the use of profiled hot plates. Annu Tech Conf ANTEC Conf Proc. 1997;1:1233-7.

21. Liu SJ, Cheng HF. The influence of interface geometry on the joint strengths of hot plate welded composites. J Reinf Plast Compos. 2010;29(4):497-509. https://doi.org/10.1177/0731684408099410.

22. Potente H, Tappe P. Scale-up laws in heated tool butt welding of HDPE and pp. Polym Eng Sci. 1989;29(23):1642-8. https://doi. org/10.1002/pen.760292304.

23. Potente H, Natrop J. Computer-Aided optimization of the parameters of heated-tool butt welding. Polym Eng Sci. 1989;29(23):1649-54. https://doi.org/10.1002/pen.760292305.

24. Potente H, Schöppner V, Hoffschlag R, Gövert S, Schnieders J. In-line process optimization of hot-tool welding using innovative actuation concept. Annu Tech Conf ANTEC Conf Proc. 2009;1:745-9.

25. Schnieders J, Büssing M, Potente H. High speed hot plate welding. Annu Tech Conf ANTEC Conf Proc. 2006;1:2216-20.

26. Nonhof CJ. Optimization of hot plate welding for series and mass production. Polym Eng Sci. 1996;36(9):1184-95. https://doi.org/ 10.1002/pen.10512.

27. Cocard M, Grozav I, Iacob M, Caneparu A. Establishing the optimum welding procedure for PE 100 polyethylene pipelines using the Response Surface Design. Mater Plast. 2009;46(4):452-7.

28. Poopat B, Wu C-Y, Benatar A, Park JB. Optimization of contact hot plate welding of HDPE. Annu Tech Conf ANTEC Conf Proc. 1999;1:1386-90.

29. Poopat B, Benatar A. Gas-assisted non-contact hot plate welding of HDPE. Annu Tech Conf ANTEC Conf Proc. 2002;1:879-84.

30. Mokhtarzadeh A, Wu CY, Benatar A. Comparison of hot plate and vibration welding of PMMA to Polycarbonate. Annu Tech Conf ANTEC Conf Proc. 2008;1:851-61.

31. Mokhtarzadeh A, Benatar A, Wu CY. Comparison of hot plate, vibration, infrared and combined infrared with vibration welding of ASA. Annu Tech Conf ANTEC Conf Proc. 2011;1:1793-8.

32. Riahi M, Kooshayan K, Ghanati MF. Analysis of effect of pressure and heat on mechanical characteristics of butt fusion welding of polyethylene pipes. Polym Plast Technol Eng. 2011;50(9):907-15. https://doi.org/10.1080/03602559.2011.551982.

33. Oliveira MJ, Duarte FM, Tchalamov D, Cunha AM. Hot plate welding of glass reinforced polypropylene. Annu Tech Conf ANTEC Conf Proc. 2001;1:1251-5.

34. Wood AS. The butt-fusion welding of polymers. Chem Eng Sci. 1993;48(17):3071-82. https://doi.org/10.1016/0009-2509(93) 80173-N.

35. Yoo JH, Choi S, Nam J, Ahn KH, Oh JS. Numerical analysis of the heat transfer and fluid flow in the butt-fusion welding process. Korea-Australia Rheol J. 2017;29(1):37-49. https://doi.org/ 10.1007/s13367-017-0005-3. 
36. Ezekoye OA, Lowman CD, Fahey MT, Hulme-Lowe AG. Polymer weld strength predictions using a thermal and polymer chain diffusion analysis. Polym Eng Sci. 1998;38(6):976-91. https://doi. org/10.1002/pen.10266.

37. Nieh JY, Ni J, Lee J. Hot plate welding of Polypropylene. Part II: process simulation. Polym Eng Sci. 1998;38(7):1133-41. https:// doi.org/10.1002/pen.10280.

38. Lee BY, Kim JS, Lee SY, Kim YK. Butt-welding technology for double walled Polyethylene pipe. Mater Des. 2012;35:626-32. https://doi.org/10.1016/j.matdes.2011.10.014.

39. Savija I, Culham JR, Yovanovich MM. Effective thermophysical properties of thermal interface materials: part I-definitions and models. Adv Electron Packag. 2003;2:189-200. https://doi.org/ 10.1115/IPACK2003-35088.

40. Kim G, Kim T, Jeong S. A study on thermal characteristics according to thermal contact resistance in hot plate welding process. In: 2009 IEEE Inte Sym Ind El 2009, pp. 1990-1995. https:// doi.org/10.1109/ISIE.2009.5214086

41. Myers TG, Mitchell SL, Muchatibaya G. Unsteady contact melting of a rectangular cross-section material on a flat plate. Phys Fluids. 2008;20: 103101. https://doi.org/10.1063/1.2990751.

42. Poslinski AJ, Stokes VK. Steady melting of rectangular thermoplastic bars induced by hot contacting surfaces. Polym Eng Sci. 1992;32(16):1147-62. https://doi.org/10.1002/pen.760321612.

43. Wałęsa K, Biszczanik A, Malujda I, Wilczyński D. Assumptions for modelling of the hot plate welding process considering the automatic welding machine design. Machine Modelling and Simulation 2020 Conference Proceedings (bin press).

44. Klimpel A. Welding of termoplastics materials. Gliwice: Wydawnictwo Politechniki Śląskiej; 2000. (in Polish).

45. Wałęsa K, Malujda M, Górecki J, Wilczyński D. The temperature distribution during heating in hot plate welding process. MATEC Web Conf. 2019;254:02033. https://doi.org/10.1051/matecconf/ 201925402033.

46. Gruin I. Polymers. Warszawa: Państwowe Wydawnictwo Naukowe; 2003. (in Polish).

47. Wirpsza Z. Polyurethanes: chemical composition, technology, application. Warszawa: Wydawnictwo Naukowo-Techniczne; 1991. (in Polish).

48. Parasiewicz W, Rzymski WM. Elastomers and rubbers industry. Łódź: IPGUM Piastów-Łódź; 2006. (in Polish).

49. Qi HJ, Boyce MC. Stress-strain behaviour of thermoplastic polyurethanes. Mech Mater. 2005;37:817-39. https://doi.org/10.1016/j. mechmat.2004.08.001.

50. Boyce MC, Kear K, Socrate S, Shaw K. Deformation of thermoplastic vulcanizates. J Mech Phys Solid. 2001;49:1073-98. https:// doi.org/10.1016/S0022-5096(00)00066-1.

51. Kukla M, Warguła Ł, Talaśka K, Wojtkowiak D. Magnetorheological elastomer stress relaxation behaviour during compression: experiment and modelling. Materials. 2020;13(21):4795. https:// doi.org/10.3390/ma13214795.

52. Drozdov AD, Christiansen JC. Constitutive equations for the nonlinear viscoelastic and viscoplastic behaviour of thermoplastic elastomers. Int J Eng Sci. 2006;44:205-26. https://doi.org/10. 1016/j.ijengsci.2005.12.002.

53. Wang Y, Luo W, Huang J, Peng C, Wang H, Yuan C, Chen G, Zeng B, Dai L. Simplification of hyperelastic constitutive model and finite element analysis of Thermoplastic Polyurethane Elastomers. Mactomol Theoret Simul. 2020;29:2000009. https://doi. org/10.1002/mats.202000009.

54. Lambert-Diani J, Rey C. New phenomenological behaviour laws for rubbers and thermoplastic elastomers. Eur J Mech A/Solids. 1999;18:1027-43. https://doi.org/10.1016/S0997-7538(99) 00147-3.

55. Das S, Chowdhury SR, Roy D. A constitutive model for thermoplastics based on two temperatures. Eur J Mech A/Solids.
2018;72:440-51. https://doi.org/10.1016/j.euromechsol.2018. 06.010 .

56. Eberlein R, Pasieka L, Rizos D. Validation of advanced constitutive models for accurace FE modelling of TPU. Adv Mater Lett. 2019;10(12):893-8. https://doi.org/10.5185/amlett.2019.0031.

57. Henze O. Increasing of the end-use temperature of TPU products. Annu Tech Conf ANTEC Conf Proc. 2005;1:3616-9.

58. Yildirim E, Yurtsever M, Wilkes GL, Yilgör I. Effect of intersegmental interactions on the morphology of segmented polyurethanes with mixed soft segments: a coarse-grained simulation study. Polymer. 2016;90:204-14. https://doi.org/10.1016/j.polym er.2016.03.008.

59. Krawiec P, Różański L, Czarnecka-Komorowska D, Warguła Ł. Evaluation of the thermal stability and surface characteristics of Thermoplastic Polyurethane V-Belt. Materials. 2020;13(7):1502. https://doi.org/10.3390/ma13071502.

60. Wałęsa K, Mysiukiewicz O, Pietrzak M, Górecki J, Wilczyński D. Preliminary research of the thermomechanical properties of the round drive belts. MATEC Web Conf. 2019;254:06007. https:// doi.org/10.1051/matecconf/201925406007.

61. Wałęsa K, Malujda I, Górecki J. Experimental research of the mechanical properties of the round drive belts made of thermoplastic elastomer. IOP Conf Ser Mater Sci Eng. 2020;776(1): 012107. https://doi.org/10.1088/1757-899X/776/1/012107.

62. Wałęsa K, Malujda I, Wilczyński D. Experimental research of the thermoplastic belt plasticizing process in the hot plate welding. IOP Conf Ser Mater Sci Eng. 2020;776(1): 012011. https://doi. org/10.1088/1757-899X/776/1/012011.

63. Wilczyński K. Rheology in polymer processing. Warszawa: Wydawnictwo Naukowo-Techniczne; 2001. (in Polish).

64. Dziubiński M, Kijański T, Sęk J. Theoretical basis and measurement methods of rheology. Łódź: Wydawnictwo Politechniki Łódzkiej; 2014. (in Polish).

65. Stabik J. Selected problems of rheology of plasticized filled polymers. Gliwice: Wydawnictwo Politechniki Śląskiej; 2004. (in Polish).

66. Hu J, Mo R, Jiang X, Sheng X, Zhang X. Towards mechanical robust yet self-healing polyurethane elastomers via combination of dynamic main chain and dangling quadruple hydrogen bonds. Polymer. 2019;183: 121912. https://doi.org/10.1016/j.polymer. 2019.121912

67. Knitter M, Dobrzyńska-Mizera M. Mechanical properties of isotactic polypropylene modified with thermoplastic potato starch. Mech Compos Mater. 2015;51(2):245-52. https://doi.org/10.1007/ s11029-015-9496-5.

68. Kiljański T. Methods of resilient properties measurement. Inż Ap Chem. 2014;53(5):344-6 (in Polish).

69. Yuegang L, Zhuo M, Yacheng W, Peibo L, Yize S. Analysis and modeling of viscosity for aqueous Polyurethane dispersion as a function of shear rate, temperature and solid content. ACS Omega. 2020;5:26237-44. https://doi.org/10.1021/acsomega.0c03959.

70. Sopade PA, Halley P, Bhandari B, D'Arcy B, Doebler C, Caffin N. Application of the Williams-Landel-Fery model to the viscosity-temperature relationship of Austrialian honeys. J Funct Eng. 2002;56:67-75. https://doi.org/10.1016/S0260-8774(02)00149-8.

71. Perko L, Friesenbichler W, Obendauf W, Buchebner V, Chaloupka G. Elongational viscosity of rubber compounds and improving corresponding models. Adv Prod Eng Manuf. 2013;8(2):126-33. https://doi.org/10.14743/apem2013.2.160.

72. Carslaw HS, Jeager JC. Conduction of heat in solids. Oxford: At the Clarendon Press; 1959.

Publisher's Note Springer Nature remains neutral with regard to jurisdictional claims in published maps and institutional affiliations. 